Review

\title{
Allicin: Chemistry and Biological Properties
}

Jan Borlinghaus ${ }^{1}$, Frank Albrecht ${ }^{1}$, Martin C. H. Gruhlke ${ }^{1}$, Ifeanyi D. Nwachukwu ${ }^{2}$ and Alan J. Slusarenko ${ }^{1, *}$

1 Department of Plant Physiology, RWTH Aachen University, 52056 Aachen, Germany

2 Department of Human Nutritional Sciences, University of Manitoba, Winnipeg, MB R3T2N2, Canada

* Author to whom correspondence should be addressed; E-Mail: alan.slusarenko@bio3.rwth-aachen.de; Tel.: +49-0-241-80-26650; Fax: +49-0-241-80-22395.

Received: 23 June 2014; in revised form: 24 July 2014 / Accepted: 28 July 2014 /

Published: 19 August 2014

\begin{abstract}
Allicin (diallylthiosulfinate) is a defence molecule from garlic (Allium sativum L.) with a broad range of biological activities. Allicin is produced upon tissue damage from the non-proteinogenic amino acid alliin (S-allylcysteine sulfoxide) in a reaction that is catalyzed by the enzyme alliinase. Current understanding of the allicin biosynthetic pathway will be presented in this review. Being a thiosulfinate, allicin is a reactive sulfur species (RSS) and undergoes a redox-reaction with thiol groups in glutathione and proteins that is thought to be essential for its biological activity. Allicin is physiologically active in microbial, plant and mammalian cells. In a dose-dependent manner allicin can inhibit the proliferation of both bacteria and fungi or kill cells outright, including antibiotic-resistant strains like methicillin-resistant Staphylococcus aureus (MRSA). Furthermore, in mammalian cell lines, including cancer cells, allicin induces cell-death and inhibits cell proliferation. In plants allicin inhibits seed germination and attenuates root-development. The majority of allicin's effects are believed to be mediated via redox-dependent mechanisms. In sub-lethal concentrations, allicin has a variety of health-promoting properties, for example cholesterol- and blood pressure-lowering effects that are advantageous for the cardio-vascular system. Clearly, allicin has wide-ranging and interesting applications in medicine and (green) agriculture, hence the detailed discussion of its enormous potential in this review. Taken together, allicin is a fascinating biologically active compound whose properties are a direct consequence of the molecule's chemistry.
\end{abstract}

Keywords: garlic (Allium sativum); reactive sulfur species; apoptosis; redox; antimicrobial; cancer; root growth 


\section{Introduction}

Allicin, a sulfur-containing natural compound with many different biological properties is responsible for the typical smell and taste of freshly cut or crushed garlic. The general, though not entirely accurate, perception of natural products as mild and largely harmless in comparison to their chemically synthesized counterparts, has been suggested as one of the reasons for their growing preference by consumers, as well as their increasingly popular use in medicine and agriculture [1]. While the pharmaceutical industry in recent decades has largely focused on high-throughput biochemical screening programmes for the discovery and development of new drugs, the use of natural products for medicinal and antimicrobial purposes is an ancient practice [2]. For instance, the oldest medical resource available contains evidence of the prophylactic and therapeutic use of hundreds of plants and plant products [3]. Written on tablets of clay in cuneiform ca. $2600 \mathrm{BC}$, this ancient Mesopotamian compendium includes prescriptions for the use of Papaver somniferum (poppy juice), Glycyrrhiza glabra (liquorice), Cedrus species etc. for the treatment of common ailments and parasitic infections. Other ancient texts like the Egyptian Codex Ebers (Ebers Papyrus), the Greek "magical papyra" and the Chinese Materia Medica are also replete with records of the use of plants and plant extracts in medicine [3,4]. While the Ebers Papyrus and the "magical papyri" precisely mention the use of extracts from garlic for medicinal purposes, Virgil, the first century BC Roman poet, highlighted their use in treating snake bites in his Second Idyll [5], and the famous Greek physician, Hippocrates, described their efficacy in treating pneumonia and in wound healing in his Corpus Hippocraticum [6]. Although onions are the most widely used Allium and one of the world's most consumed foods [4], it is their more pungent relative garlic, widely notorious for its rather feisty interaction with man's olfactory receptors, that has received greater attention from investigators. From its various uses as a vampire repellent and an antidote for dog bites in older times, to its more recent perinatal recruitment by Greek midwives for the purpose of warding off "the evil eye" in labour rooms [4], garlic's journey through time and history is as rich as it is colourful. Speculations abound concerning the origin of the cultivation of Allium - The genus to which garlic (Allium sativum), leek (A. porrum), onion (A. cepa), chives (A. schoenoprasum) and well over 700 other species belong, but there are early documented reports from Afghanistan, Kazakhstan, Kyrgyzstan, Pakistan, Tajikistan, Turkmenistan, Uzbekistan, and Northern Iran [7,8]. While garlic's culinary, therapeutic and even spiritual value has been recognized and acknowledged for centuries, it was not until 1944 when Cavallito and Bailey [9] isolated and described the properties of allicin, the compound responsible for garlic's characteristic pungent odour, that researchers gained a clearer insight into the chemical wonder carefully packaged by nature in the composite bulbs of this edible Allium, and thus began decades of extensive research on allicin, "the heart of garlic" [10].

\section{Biosynthesis of Allicin}

Allicin is a thiosulfinate, and its structure was determined by Stoll and Seebeck in 1948 [11]. In nature allicin is produced after damage of the plant tissue by an enzymatic reaction. The precursor of allicin is the non-proteinogenic amino acid alliin (S-allyl-L-cysteine sulfoxide) [12]. Alliin and other S-alkyl-L-cysteine sulfoxides are hydrolysed by the enzyme alliinase [13,14], and in the case of alliin 
this reaction leads to production of dehydroalanine and allyl sulfenic acid. Two molecules of allyl sulfenic acid condense spontaneously to one molecule of allicin [15]. Alliin is found in garlic (Allium sativum) and ramsons (Allium ursinum) [11]. Interestingly, onion (Allium cepa) does not synthesize alliin, but its isomer isoalliin (trans-(+)-S-(1-propenyl)-L-cysteine sulfoxide) [16]. The biosynthetic route to alliin is still not clear. Pioneering work by Granroth [13], who reported two possible biosynthetic pathways based on radioactive labeling experiments, has up to now not been bettered. His findings are shown in Scheme 1.

Scheme 1. Biosynthesis of allicin: Based on Granroth's work there are two possible biosynthetic pathways leading to S-allyl-cysteine. The detection of ${ }^{14} \mathrm{C}$-labeled S-allyl-cysteine after feeding plants with ${ }^{14} \mathrm{C}$-labeled serine and the incorporation of various alkyl mercaptans led Granroth to the conclusion that serine is one possible substrate for S-allyl-cysteine biosynthesis. An alternative pathway leads from glutathione to S-allyl-cysteine. This was confirmed by the detection of S-allyl-glutathione and S-allyl- $\gamma$-glutamyl-cysteine. The source of the allyl-group is still unknown. S-allyl-cysteine is oxidised to alliin, which is the "inactive" precursor of allicin. Alliin is enzymatically hydrolysed to produce allyl sulfenic acid which condenses spontaneously to allicin.

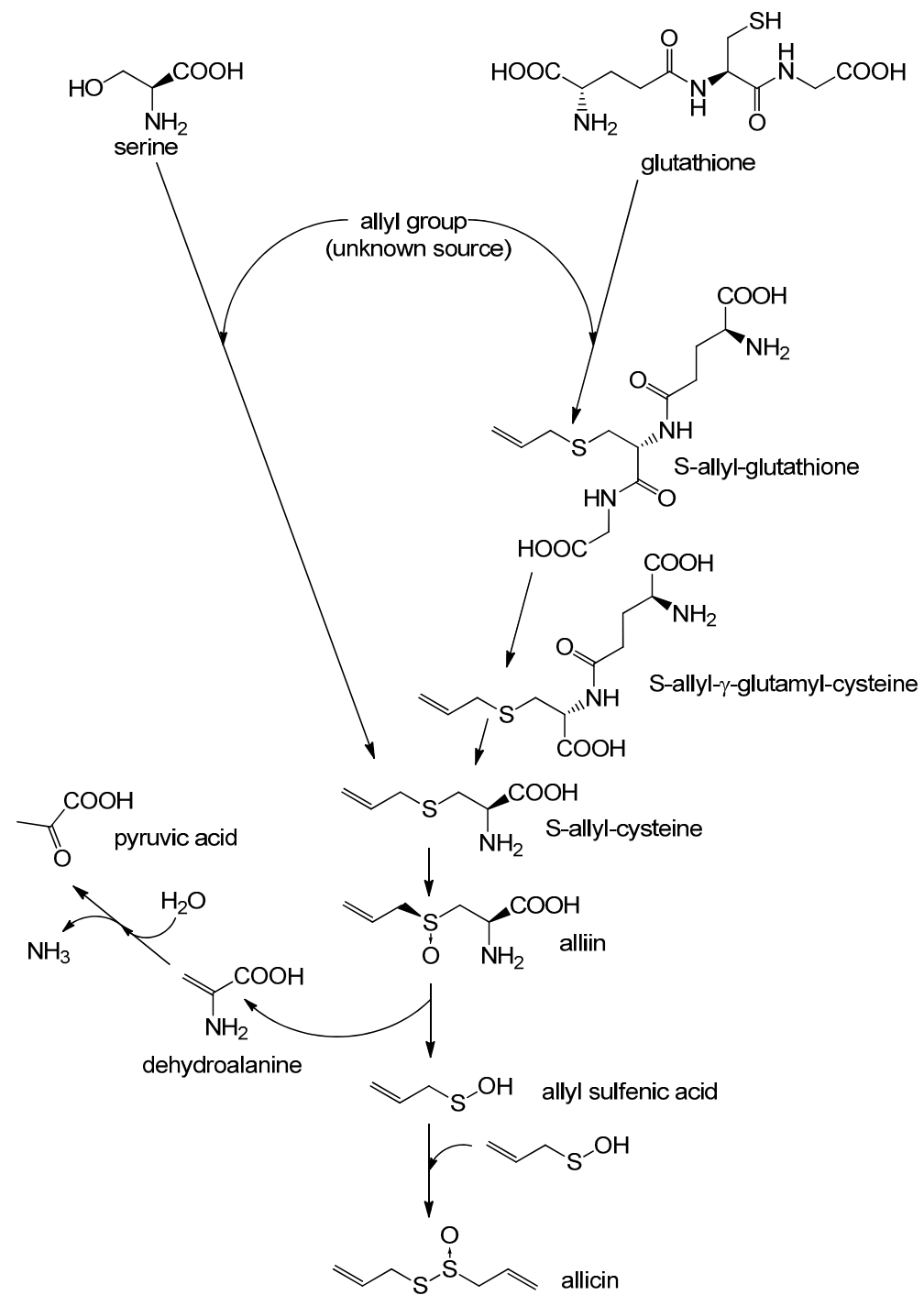


In particular determining the origin of the double bond in alliin is problematic. Granroth was able to show that the double bond in isoalliin originated from methacrylic acid, but this was not the case for alliin, so the source of alliin's double bond remains unknown. Furthermore, Granroth showed that onion is able to produce alliin when fed with allyl mercaptan or boiled garlic extract. Granroth also showed that not only cysteine but also serine can be a source of the amino acid part of alliin. This was achieved by feeding onion with ${ }^{14} \mathrm{C}$-labeled serine and a variety of thiols. In each case Granroth reported a ${ }^{14} \mathrm{C}$-labeled S-alkyl-L-cysteine sulfoxide, with the alkyl group corresponding to the supplied thiol. In the laboratory allicin can by synthesized by oxidation of diallyl disulfide (DADS) with hydrogen peroxide [17], magnesium monoperoxyphthalate [18] or chloroperbenzoic acid [19]. The oxidation of DADS by hydrogen peroxide is shown in Scheme 2 and reviewed by Ilić et al. [15].

Scheme 2. Synthesis of allicin according to Stoll and Seebeck: (A) Diallyl disulfide (distilled under reduced pressure) is mixed with acetic acid and hydrogen peroxide. Because hydrogen peroxide reacts very slowly with diallyl disulfide, acetic acid is needed as a catalyst. Peracetic acid (ethaneperoxoic acid) is formed, which is able to oxidize diallyl disulfide to allyl sulfenic acid. This reaction also leads to the production of allyl radicals which can react with hydrogen peroxide to form allyl sulfenic acid and hydroxyl radicals. The latter are able to react with diallyl disulfide to form allyl sulfenic acid and allyl radicals again. Two molecules of allyl sulfenic acid condense to allicin. This reaction mechanism is not only suitable to synthesize allicin but also other thiosulfinates. (B) To produce allicin by an enzymatic reaction alliin is needed. Cysteine is mixed with allyl bromide in an alkaline $(\mathrm{NaOH})$ mixture of water and ethanol to obtain S-allyl cysteine. The latter can be oxidized with hydrogen peroxide to produce alliin. By an enzymatic reaction of alliin with alliinase, allicin is formed.

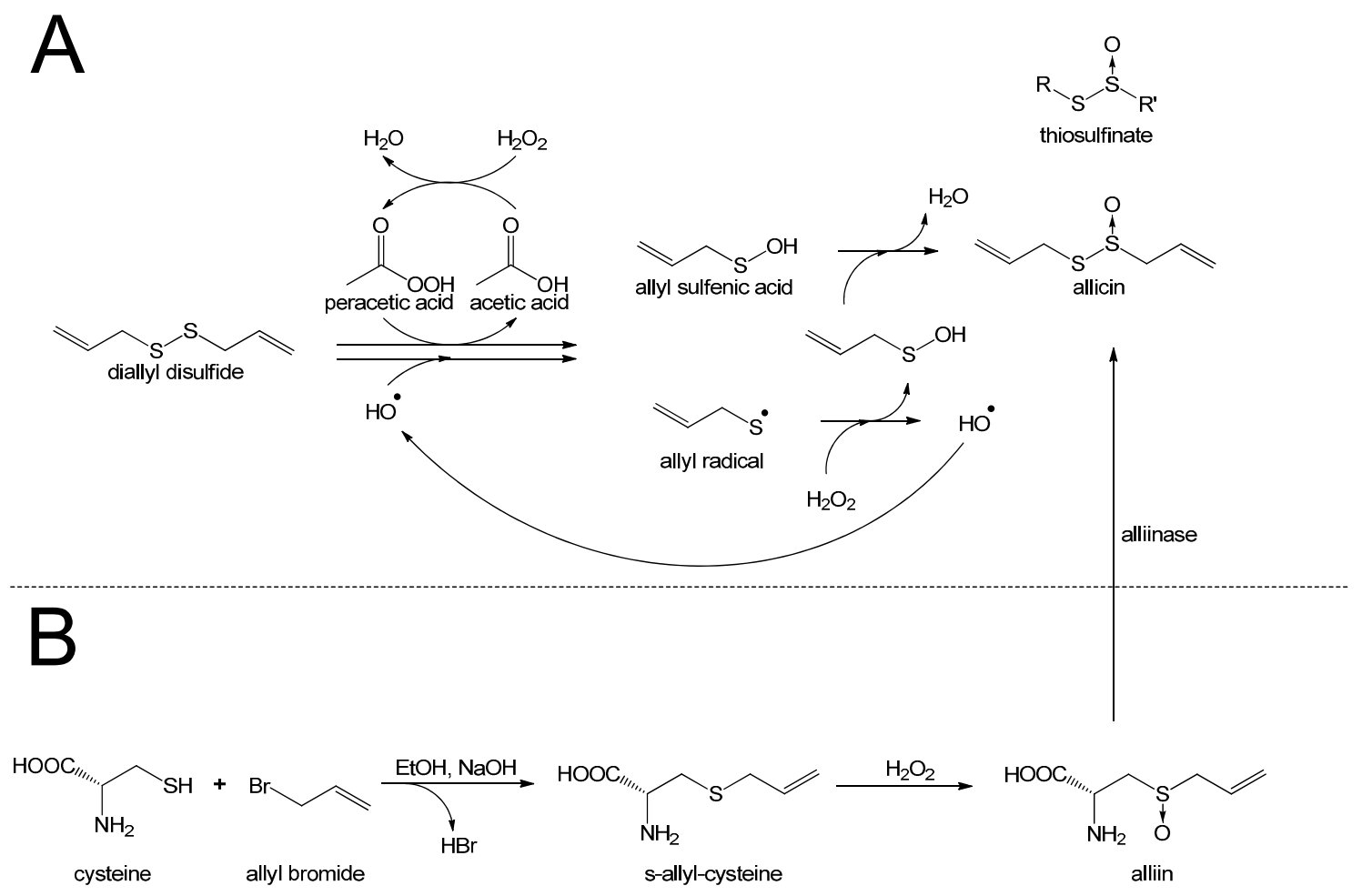


Further to the chemical synthesis of allicin, protocols for its enzymatic production in vitro have been published [20,21]. The substrate alliin can be extracted from garlic gloves or synthesized from cysteine by alkylation with allyl bromide followed by oxidation with hydrogen peroxide [11,14]. Because of allicin's high reactivity and low thermal stability it is difficult to obtain and store pure allicin without contamination by related compounds like ajoene, vinyldithiine or polysulfane [22]. Nevertheless, in dilute aqueous solutions at $-70{ }^{\circ} \mathrm{C}$ preparations have been reported to be stable over years (no loss in two years) [5].

\section{Redox-Chemistry Pertaining to Allicin}

Subcellular compartments need to have regulated but individually diverse conditions to maintain biochemical cellular processes for metabolism. Thus, ionic concentration, $\mathrm{pH}$ and an appropriate redox potential need to be carefully maintained. Redox reactions are common in cells and can be recognized because the formal redox state of the atoms in the reactants changes. The concept of redox potential is an aspect of Thermodynamics and the local redox potential will determine whether a particular redox reaction is possible and in which direction a reversible redox reaction can proceed and what equilibrium point it might reach [23,24]. In a biological context many reactions are occurring simultaneously and are present in integrated networks. Thus, although thermodynamic concepts inform us about the possibility, direction and extent of a particular reaction, the picture is incomplete without a consideration of the relative rates of networked reactions, i.e., the Kinetics. For example, a given redox reaction may not be in equilibrium with the redox environment in the cellular compartment because one of the products is rapidly further metabolized or an enzyme catalyzing the reverse reaction proceeds very rapidly whereas the initial reaction is very slow [25]. Nevertheless, the global redox potential in a cellular compartment will influence the reactivity of accessible redox-active cellular metabolites and by this will affect the cell's chemistry.

In general, healthy cells have a negative cytosolic redox potential - that means the cytosol is in a reduced/reducing state. The cytosolic redox potential of baker's yeast (Saccharomyces cerevisiae) is quoted with values between $-220 \mathrm{mV}$ and $-320 \mathrm{mV}$ [26]. The cellular redox potential is controlled largely by the GSH/GSSG redox couple (glutathione pool), along with the NAD(P)H/NAD(P) ${ }^{+}$ couples and thioredoxins. Glutathione is a tripeptide consisting of glutamic acid, cysteine and glycine. It was first found by Rey-Pailhade as a biological substance with reducing properties, when he used cell extracts to reduce sulfur to hydrogen sulfide. He named it philothione [27]. Glutathione got its present name from Frederick Hopkins, who, however, thought it to be a dipeptide of glutamic acid and cysteine [28]. Glutathione's structure was solved by Harington and Mead in 1935 [29]. In cells GSSG is reduced to GSH by glutathione reductase (GR) and NADPH [30,31]. GR is a key enzyme in cellular redox homoeostasis [32,33].

Allicin is a reactive sulfur species (RSS) [23] with oxidizing properties, and it is able to oxidize thiols in cells, e.g., glutathione and cysteine residues in proteins. A more oxidized glutathione pool leads to a higher cellular redox potential. Oxidation of protein thiols can lead to changes in protein structure, for example through disulfide bond formation (for details see Scheme 3). Redox-triggered structural changes in proteins can lead to loss or gain of function. Such effects are already known for the plant protein NPR1, which is a key protein in pathogen-triggered immunity [34] and in yeast 
(S. cerevisiae) for YAP1, which is a redox-sensitive transcription factor coordinating the oxidative stress response [35]. YAP1 is equivalent to the redox regulated mammalian Nrf2/Keap1/ARE system [36]. Detailed investigations to characterize the allicin-dependent redoxome are currently underway in our group.

Scheme 3. Overview of redox chemistry of allicin and cellular thiols: Allicin (1) is able to react with cellular thiols like glutathione (GSH) and cysteine-containing proteins. Reaction with proteins leads to S-allyl-mercapto-proteins (2) and allyl sulfenic acid (3). S-allyl-mercapto-proteins are able to react with other proteins by formation of disulfide bond-stabilised complexes (4) or to form intramolecular disulfide bonds (5). Both reactions lead to elimination of allyl mercaptan (6). Protein disulfide bonds can be reduced by cellular GSH which leads to S-glutathionyl-mercapto-proteins (7). To remove the glutathionyl residues from the proteins another GSH is needed. Allicin also reacts with GSH. This reaction leads to S-allyl-mercapto-glutathione (8) and allyl sulfenic acid (3). S-allyl-mercapto-glutathione can undergo a thiol/disulfide exchange reaction with another GSH to form GSSG and allyl mercaptan (6). Allyl sulfenic acid (3), produced in direct reactions of allicin and thiols is able to react with proteins to form S-allyl-mercapto-proteins (2), with GSH to form S-allyl-mercapto-glutathione (8), with allyl mercaptan (6) to DADS (9) or with another allyl sulfenic acid (3) to form allicin again.

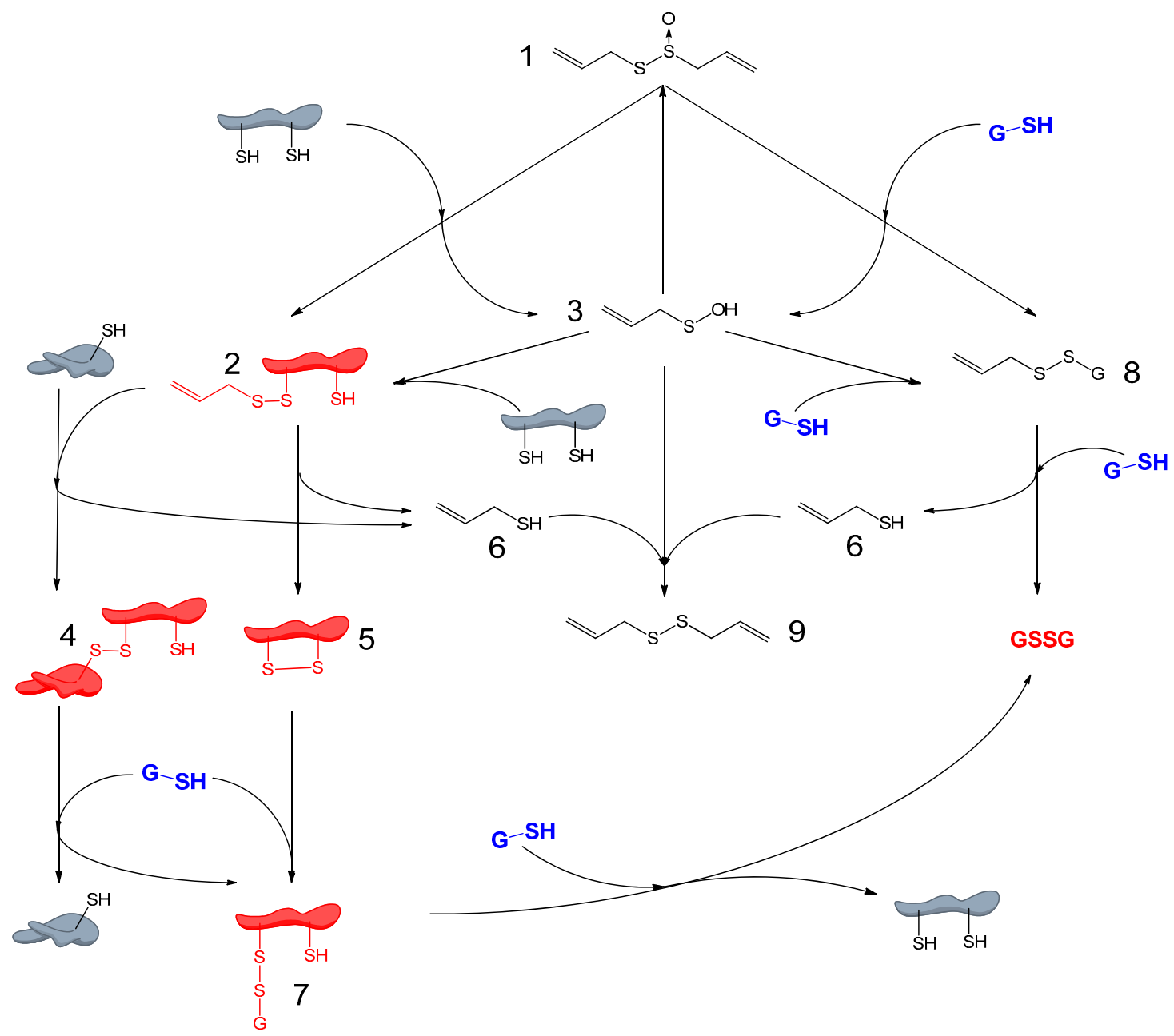




\section{Antimicrobial Activity of Allicin}

Since ancient times mankind has had to face many different kinds of disease and there was much speculation about their causes. In the Middle Ages the devil turned out to be the usual suspect, however, in the 19th century Robert Koch proved that bacteria caused and transmitted anthrax and the Germ Theory of disease was born. Reports about the targeted use of garlic as an antimicrobial agent go back to the famous Louis Pasteur [37] and in World War I extracts of garlic were used in antibacterial and antiseptic therapeutics. Numerous scientific studies concerning the antibacterial potential of garlic have been published (for a detailed list of reports, refer to Koch and Lawson [5]).

\subsection{Allicin Is almost Exclusively Responsible for the Antimicrobial Activity of Freshly Crushed Garlic}

Isolation and testing of the organosulfur compounds from garlic for antimicrobial activity was carried out in the 1940s [9]. Neither DADS, directly formed by the decomposition of allicin, nor the diallylpolysulfanes showed any remarkable antimicrobial activity, unless used in very high concentrations. Koch and Lawson [5] determined the minimal concentration of organosulfur compounds found in crushed garlic needed to inhibit the growth of Escherichia coli and Staphylococcus aureus. According to their results, approximately $35 \times$ more DADS (6.15 mM) was needed to inhibit the growth of these two bacteria compared to allicin $(0.17 \mathrm{mM})$.

The fact that DADS, as one of allicin's direct decomposition products, has a significantly lower antimicrobial activity indicates that the thiosulfinate-group (Scheme 2) plays an important role in that activity since it is lost during the reduction of allicin to DADS. Small et al. [38] considered thiosulfinates as " $a$ new class of compounds of which the antibacterial agent of garlic [allicin] represents the prototype" and chemically synthesized different thiosulfinates, including allicin itself. The thiosulfinate derivatives differed in the alkyl groups that were attached to the thiosulfinate group in chain length as well as in branching. They tested these on twenty different bacterial isolates by elucidating the minimal concentration needed for a bacteriostatic effect in liquid culture. Thereby, two general observations could be made: Firstly, branching of the alkyl groups resulted in a lowered activity. For example, two times more isopropyl thiosulfinate derivative (effective concentrations ranging from 10 to $>1200 \mu \mathrm{M}$ ) is needed for a bacteriostatic effect than of the $n$-propyl thiosulfinate derivative (ranging from 10 to $600 \mu \mathrm{M}$ ). Of all the derivatives tested, the most branched alkyl group attached to the thiosulfinate, tert-butyl-ethyl thiosulfinate, showed the weakest activity of all thiosulfinates (ranging from 60 to $>1200 \mu \mathrm{M}$ ). The most effective thiosulfinate turned out to be $n$-pentyl-thiolsulfinate (ranging from 0.7 to $130 \mu \mathrm{M}$ ) which was slightly more effective than allicin (ranging from 50 to $150 \mu \mathrm{M}$ ) and furthermore, it was much more stable than allicin due to the lack of double bonds. Secondly, the bacteriostatic effect of thiosulfinates against Gram positive bacteria became stronger with increasing carbon chain length but weaker against Gram negative bacteria.

Depending on the organism and the antibiotic used, on a mol-for-mol basis the effectivity of conventional antibiotics like $\beta$-lactams (penicillin and derivatives like ampicillin) or glycosidic antibiotics like kanamycin are comparable to allicin [9,39,40] (Figure 1). However, allicin is active against a broader spectrum of microorganisms than most of the commonly used antibiotics. For example, allicin is active against both Gram positive and Gram negative bacteria, whereas penicillin is 
practically not effective against the latter [9]. Allicin is also active against human pathogens that are resistant against certain antibiotics. A prominent case of such a germ is methicillin resistant Staphylococcus aureus (MRSA) - the chief culprit in many hospital infections. It has been shown that this important pathogen is effectively inhibited by allicin [41].

Figure 1. Plate diffusion test. Antibacterial activity against E. coli $\mathrm{DH} 5 \alpha$ demonstrated on seeded agar plates by different antibiotics is indicated by clear zones where growth inhibition has occurred. Freshly grown $E$. coli cells $\left(\mathrm{OD}_{600}=0.2,300 \mu \mathrm{L}\right)$ were embedded in $20 \mathrm{~mL}$ warm agar in a Petri dish (diameter $9 \mathrm{~cm}$ ). Afterwards, holes (diameter $0.6 \mathrm{~cm}$ ) were punched out and filled with $40 \mu \mathrm{L}$ of antibiotic solution at the $\mathrm{mM}$ concentrations indicated. Pictures were taken after $24 \mathrm{~h}$ of incubation in the presence of the antibiotics. (A) kanamycin; (B) allicin; and (C) ampicillin.
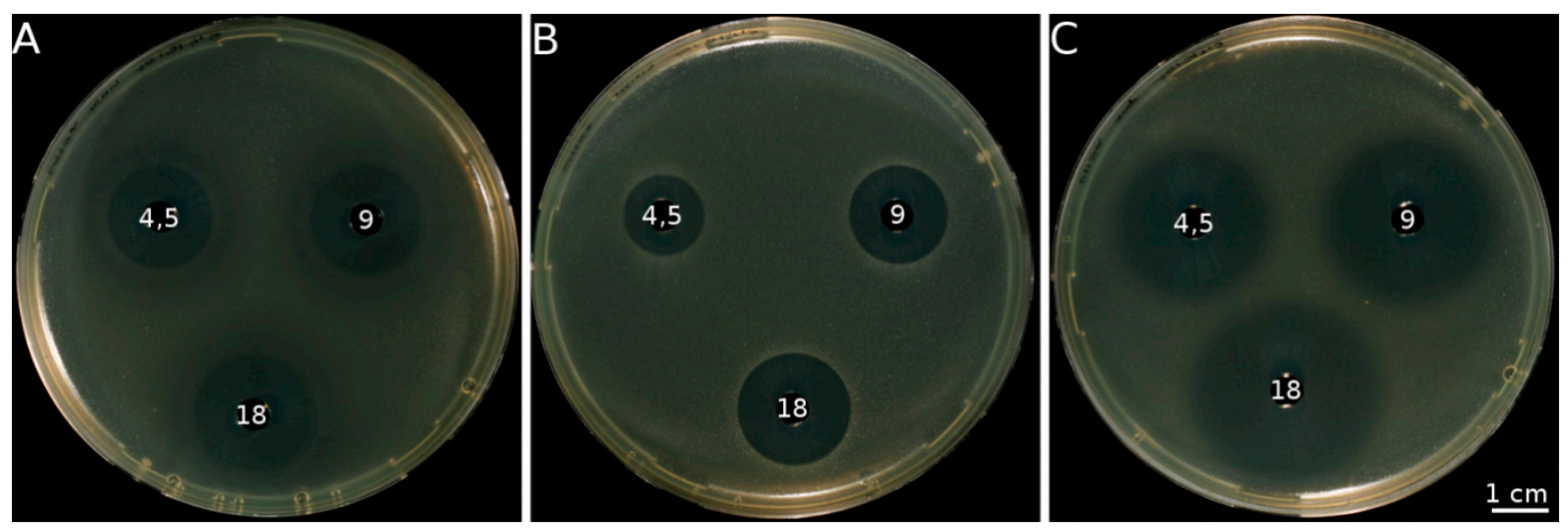

In several case studies the antimicrobial activity of allicin has been investigated by using garlic extract rather than pure allicin. In general, the antimicrobial activity of garlic extract correlates with the allicin content [42], and if the formation of allicin is inhibited during extraction [12], or if allicin is removed [43], the extract loses its antimicrobial activity. However, Fujisawa et al. [40] demonstrated that on a mol-for-mol basis, an allicin-containing extract of garlic was twice as effective as synthetic allicin in inhibiting Staphylococcus aureus. These findings indicate either synergistic effects of allicin with other components in the extract, or the additional action of other antimicrobial compounds. Thus, in every case study of allicin activity, the source of allicin (preferably pure allicin) should be taken into consideration. Some bacteria that were tested with either garlic extract and/or pure allicin are listed in Table 1.

\subsection{A Closer Look at the Basis for Antimicrobial Activity of Allicin}

After it was clearly shown by Cavallito and Bailey [9] that allicin is almost exclusively responsible for the antibiotic properties of garlic, the question of the mechanism of allicin's antibiotic activity arose.

The fact that a compound possesses antimicrobial activity is based on two principal features. Firstly, the compound must be able to reach potential targets and, if these are intracellular, that means it must be able to get inside the microbial cell. In the case of bacteria, an antibiotic has to penetrate the bacterial cell wall and the cell membrane. In addition to these two boundaries, the slime layers or capsules of certain bacteria can constitute an extra layer of resistance [44]. Following the arrival of the 
antibiotic in the cell, it must have a target that, if attacked, leads to cell inactivity or cell death. Miron et al. [45] investigated the permeability of artificial and natural phospholipid membranes to allicin and demonstrated that allicin readily diffuses across these membranes.

Table 1. Examples of allicin's antibacterial activity.

\begin{tabular}{|c|c|c|c|c|}
\hline Bacteria & Source of Allicin & Amount of Allicin & $\begin{array}{l}\text { Experimental } \\
\text { System a,b,c,d }\end{array}$ & Reference \\
\hline \multicolumn{5}{|c|}{ Gram positive } \\
\hline \multirow[t]{2}{*}{ Bacillus spp. } & $\begin{array}{l}\text { pure allicin extracted } \\
\text { from garlic }\end{array}$ & $80 \mu \mathrm{M}$ & a & [9] \\
\hline & synthetic & $30-150 \mu \mathrm{M}$ & a & [38] \\
\hline \multirow{2}{*}{ Streptococcus spp. } & $\begin{array}{l}\text { pure allicin extracted } \\
\text { from garlic }\end{array}$ & $80 \mu \mathrm{M}$ & $\mathrm{a}$ & [9] \\
\hline & synthetic & $\begin{array}{l}\text { ranging from } 60 \mu \mathrm{M} \\
\text { to } 200 \mu \mathrm{M}\end{array}$ & $\mathrm{a}$ & {$[38]$} \\
\hline $\begin{array}{l}\text { methicillin sensitive Staphylococcus } \\
\text { aureus NBRC } 12732\end{array}$ & $\begin{array}{l}\text { synthetic and } \\
\text { garlic extract }\end{array}$ & $2.2 \times 10^{-3}-0.92 \mu \mathrm{mol}$ & $\mathrm{b}, \mathrm{c}$ & [40] \\
\hline $\begin{array}{l}\text { methicillin resistant Staphylococcus } \\
\text { aureus (clinical isolates) }\end{array}$ & garlic extract & $0.04-0.62 \mu \mathrm{mol}$ & $\mathrm{b}, \mathrm{e}$ & [41] \\
\hline \multicolumn{5}{|c|}{ Gram negative } \\
\hline \multirow{2}{*}{ Salmonella typhimurium } & $\begin{array}{l}\text { pure allicin extracted } \\
\text { from garlic }\end{array}$ & $80 \mu \mathrm{M}$ & $\mathrm{a}$ & [9] \\
\hline & $\begin{array}{l}\text { enzymatically } \\
\text { synthesized from alliin }\end{array}$ & $\begin{array}{l}\text { ranging from } 200 \mu \mathrm{M} \\
\text { to } 500 \mu \mathrm{M}\end{array}$ & $\mathrm{a}$ & [46] \\
\hline Agrobacterium tumefaciens & garlic extract & $1.72 \mu \mathrm{mol}$ & b, d & [39] \\
\hline Escherichia coli $\mathrm{K} 12$ & garlic extract & $0.52-1.72 \mu \mathrm{mol}$ & $\mathrm{b}, \mathrm{c}$ & [39] \\
\hline $\begin{array}{l}\text { Pseudomonas syringae } \\
\text { (various pathovars) }\end{array}$ & garlic extract & $1.72 \mu \mathrm{mol}$ & $b, d$ & [39] \\
\hline Vibrio cholerae & $\begin{array}{l}\text { pure allicin extracted } \\
\text { from garlic }\end{array}$ & $80 \mu \mathrm{M}$ & $\mathrm{a}$ & [9] \\
\hline
\end{tabular}

${ }^{a}$ complete growth inhibition in liquid culture; ${ }^{b}$ growth inhibition zones; ${ }^{c}$ via soaked filter discs on top of the seeded agar, ${ }^{\mathrm{d}}$ directly pipetted onto bacteria-seeded agar or ${ }^{\mathrm{e}}$ pipetted into wells punched out of the agar.

When allicin is inside the cell, the antibiotic efficiency depends upon reaching and reacting with its targets and on the importance of those targets to the cell. In a seminal study, using logic that has stood the test of time, Cavallito and coworkers investigated the chemistry of several plant-derived antimicrobial compounds. It was found that the active principles of Allium sativum, Erythronium americanum, Asarum reflexum, Arctium minus, Ranunculus acris, Ranunculus bulbosus and of Brassica species as well as the non-plant-derived antibiotics penicillin, citrinin, gliotoxin, clavacin and pyocyanines react with cysteine. Pretreatment of these antibiotics with cysteine led to a total loss of activity against bacteria [47]. The different antibiotics were categorized into groups depending on their reactivity with cysteine residues [48]. The antibiotics were tested with cysteine residues that differed in their chemical microenvironment. In summary, certain antibiotics (group I, e.g., allicin) reacted with every cysteine residue independently of the neighbouring groups, as long as the -SH-group was freely available. Another group of antibiotics (group III, e.g., penicillin) showed increased reaction kinetics 
with cysteine if other amino-groups were adjacent to the cysteine residue, but much slower reaction kinetics if not. Pyocyanines (group II antibiotics) turned out to be in between, since they showed intermediate reaction kinetics with the cysteines tested. These experiments were prophetically significant considering the present state of knowledge on the effects of surrounding amino acids on the micro $\mathrm{p} K_{\mathrm{a}}$ values (and therefore reactivity) of cysteine residues in proteins to oxidation [25,49]. Furthermore, Cavallito's group speculated that the lower efficiency of allicin compared to penicillin and other antibiotics could be explained depending on their reactivity with cysteine residues. Since allicin reacts readily with all free cysteine residues available, it is buffered by proteins and low molecular weight thiols, independently of their importance for cellular viability. On the other hand, it was speculated that the specificity of penicillin for cysteine residues in the vicinity of amino-groups would lead to less waste of penicillin on unimportant targets, therefore making it more efficient than allicin [48]. Several case studies have subsequently reported the reactivity of allicin with thiol-containing enzymes [49-51]. For example, Wills [52] used allicin to inhibit the activity of several enzymes in vitro. Among them were important enzymes for primary metabolism like succinic dehydrogenase, hexokinase, triosephosphate dehydrogenase or alcohol dehydrogenase.

But it has to be stated that some enzymes which did not contain a thiol group were also inhibited by allicin, whereas a few enzymes containing a thiol group could not. These findings suggest that not only cysteine is a potential target for allicin. The fact that some enzymes, although containing thiol groups, are not inactivated by allicin could be explained by an adverse $\mathrm{p} K_{\mathrm{a}}$ of these cysteines which depends on the microenvironment within the protein [49], so that the reactivity of these cysteines with allicin is very weak. Rabinkov et al. [51] investigated the reaction of cysteine with allicin using RP-HPLC and NMR-analysis of the resulting products. It was shown that allicin reacted with the sulfhydryl-group of cysteine via a disulfide exchange-like reaction (Figure 2B, unstressed situation shown in Figure 2A). By demonstrating that enzymes that are irreversibly inhibited by allicin can be rescued by strong reductants, the idea of the disulfide exchange-like reaction was transferred to a working model of enzyme inhibition by allicin via the same mechanism.

\subsection{Does Allicin have an Effect on DNA-, RNA- and Protein Synthesis?}

In 1988, Feldberg et al. investigated the effect of allicin on the synthesis of DNA, RNA and proteins in Salmonella typhimurium [46]. Here, it was determined that the minimal concentration of allicin needed to inhibit the growth of $S$. typhimurium was $0.3 \mathrm{mM}$. This allicin concentration turned out to be not lethal, so that $S$. typhimurium recovered and started to grow again at a lower rate, after a lag-period of fifty minutes. He measured the uptake of $\left[{ }^{3} \mathrm{H}\right]$ labeled uridine, leucine and thymidine in allicin-stressed and unstressed control cells and observed a maximum decrease of $68 \%$ for $\left[{ }^{3} \mathrm{H}\right]$-thymidine uptake, a $65 \%$ decrease in $\left[{ }^{3} \mathrm{H}\right]$-leucine uptake and a $100 \%$ decrease in $\left[{ }^{3} \mathrm{H}\right]$-uracil uptake a few minutes after allicin had been applied to the bacteria. Since all these $\left[{ }^{3} \mathrm{H}\right]$ labeled molecules are building blocks for DNA (thymidine)-, RNA (uracil)- and protein (leucine) synthesis, Feldberg concluded that allicin affected the synthesis of these macromolecules, since there seemed to be no demand for the uptake of their precursors. In his study, however, the possibility that proteins involved in the uptake of these precursors could have been affected directly or indirectly was not investigated. For example, transport proteins could have been directly poisoned if they would have an 
exposed cysteine group that could be affected by allicin. Indirectly, another possibility could be that the energy supply for the transport proteins was not met because enzymes in metabolic pathways had been affected by allicin treatment. Unfortunately, there was no follow-up investigation on these findings, so it remains unclear if the effect observed really showed a direct decrease in DNA-, RNA- and protein synthesis.

Figure 2. Possible influence of allicin on proteins and protein synthesis. (A) protein synthesis in unstressed conditions. After translation the protein is folded into its final structure. (B) The cysteine residue that is accessible for attack (indicated in red) reacts with allicin via a disulfide exchange-reaction. The cysteine residue that is sterically blocked (indicated in blue) does not react with allicin. (C) According to Cavallito's hypothesis, allicin may attack cysteine residues on elongating amino acid chains while the protein is still being synthesized and is not fully developed [48]. In this early stage, cysteine residues that are normally blocked for reactions with allicin (compare B) are now potential targets. Possible results may be an abortion of translation or misfolded proteins with reduced or no function.

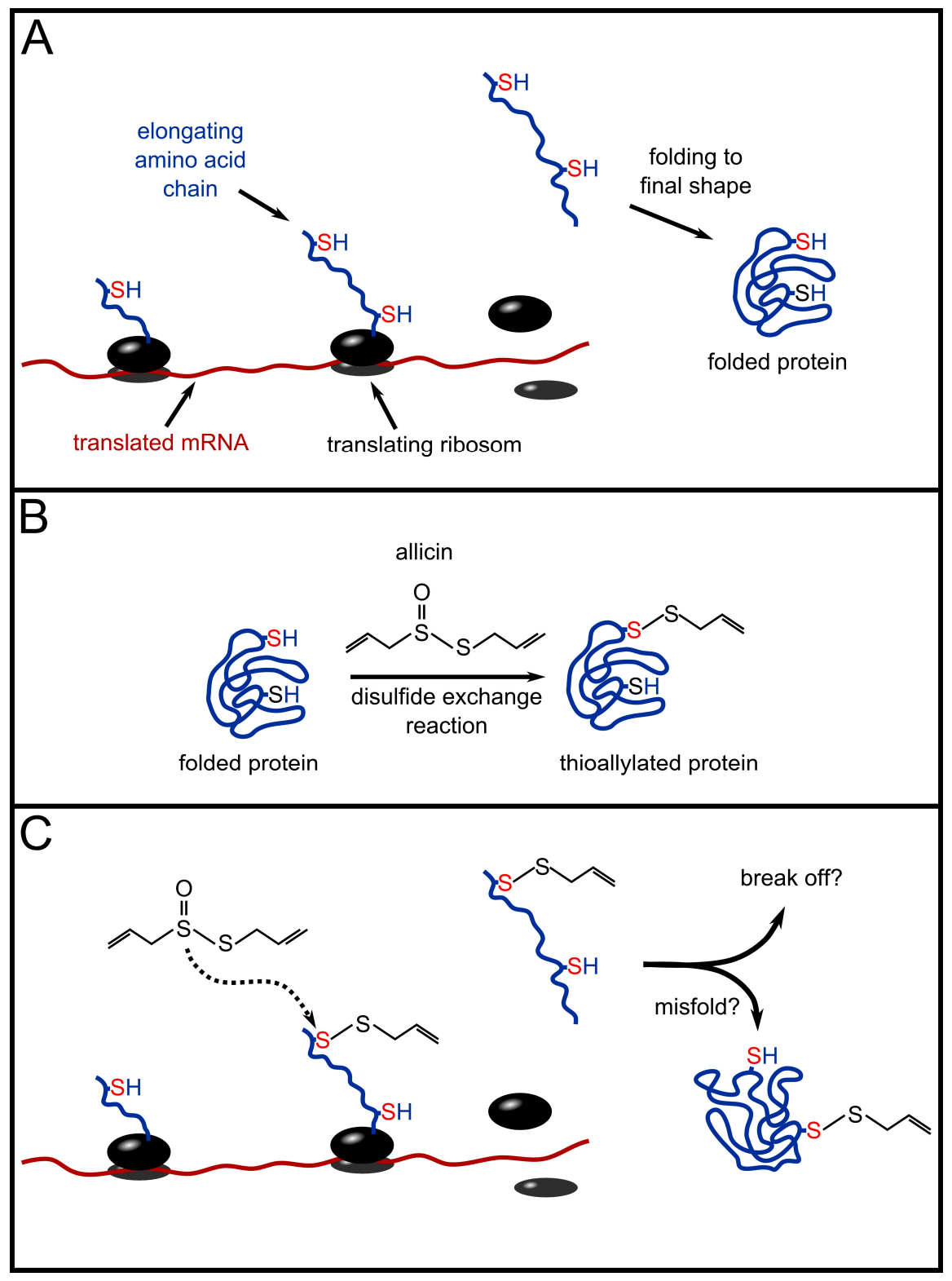




\subsection{Effect of Allicin on Fungi}

In the course of evolutionary time garlic plants developed the alliin/alliinase system, responsible for the production of allicin in freshly injured tissue, as a chemical weapon against biotic enemies. Since allicin is produced from a preformed substrate, without further expenditure of cellular energy or metabolism (i.e., passively), upon an attack by a pathogenic microbe or feeding animal, it belongs to the class of so called "phytoanticipins" [53]. In contrast, defence compounds that are produced by a plant de novo after an attack, dependent upon the expenditure of cellular energy and usually de novo gene expression (i.e., actively), are called phytoalexins (ibid). Besides bacteria, many fungal species are potential pathogens that the plant has to cope with.

Beyond its well documented strong antibacterial properties allicin also shows toxic effects towards fungal cells and is able to inhibit spore germination and hyphal growth in vivo and in vitro [39]. Some efforts have been made to utilize this activity and develop allicin for application in medical therapy and agricultural plant protection [1,54,55].

Allicin showed promising activity both in vitro and in vivo against many plant-pathogenic fungal species, including pests, which are of economic importance. For example, Botrytis cinerea, Plectospherella cucumerina, Alternaria brassicicola and Magnaporthe grisea were strongly inhibited in vitro by allicin in fresh garlic juice in a plate-diffusion assay using spore-seeded agar [39]. In further studies, seed-disinfection turned out to be an efficient and potential application of allicin. It was shown that carrot seeds, infected with Alternaria spp., were disinfected by treatment with garlic juice in a degree comparable to a commercial seed-disinfection product [1]. In another assay, germination and seedling-development of pathogen-infested wheat seeds were enhanced by treatment with garlic juice [56]. Thus, allicin seems to have a potential in seed-disinfection programmes both in ecological agriculture and under low-tech conditions (like in developing countries). Since allicin is easy to obtain from freshly damaged garlic tissue, applications in that direction would allow a plant-protection strategy according to the maxim "grow your own pesticide".

Beside this agriculture-orientated application, fungal infections of humans and animals are a focus of interest [57]. Thus, it was claimed that allicin might be the basis of a strategy to treat aspergillosis in the lung, since allicin is highly volatile and thus can be delivered to the lung by inspiration [58]. Allicin can also easily be applied topically to fungal infections of the skin and hence attempts were made to use allicin in the therapy of Candida-infections. Interestingly, allicin's activity was comparable to the frequently used antimycotic agent fluconazole [55]. There is an emerging interest in understanding the molecular basis of allicin's fungicidal properties.

Various studies of allicin's effect on baker's yeast show that it acts synergistically with other, known fungitoxic substances like copper [59-62]. Furthermore, synergistic toxicity of allicin with amphotericin B suggest an impact of allicin possibly on fungal plasma membrane [63-65].

A form of programmed cell death called apoptosis, where cells employ a genetic suicide programme, has been known for many years in multicellular organisms where it is employed in tissue turn-over and avoids inflammation responses which would usually occur when cells are damaged. Many stimuli can push cells into the apoptotic cell death programme, among others, oxidative stress. Using yeast as a model for apoptosis is a relatively new development, nevertheless, similarities to apoptotic processes in animal cells justify the transferability of the "apoptosis" term from animals to 
yeast [66]. It was shown that allicin causes an oxidation of glutathione that results in a shift of the cellular redox-potential to a range correlating, according to Schafer and Buettner [67], with the induction of apoptosis [68]. Using both cytological, biochemical and genetic assays confirmed that allicin pushes yeast cells into apoptosis via the "oxidative route" [69].

The global effects of allicin on the yeast transcriptome were reported by $\mathrm{Yu}$ et al. [69]. From micro-array experiments it was determined that allicin impaired the expression of genes coding for enzymes of amino acid metabolism (methionine, in particular), iron-uptake, the respiratory chain, thiamine-metabolism and proteasomal protein degradation [69]. The authors postulated that these results might be explained by the action of allicin on several different yeast transcription factors (YAP1, MSN2/4, RPN4, SKN7) (ibid.).

In summary, allicin shows a broad spectrum of effects on a variety of fungal species which makes a possible application of allicin in medicinal therapy and agriculture an attractive possibility. On the basis of allicin's effects on S. cerevisiae, it is apparent that the redox-effect of allicin seems to be a central, but not exclusive explanation of allicin's fungicidal activity.

\section{Allicin's Effects on Animal and Human Cells}

The variety of physiological effects makes allicin important for medicinal applications. Indeed, garlic has been used for centuries because of its therapeutic and health-promoting properties [4]. Studies have linked garlic consumption and the inclusion of garlic oils in the diet with such health-promoting benefits as the selective reduction of triacylglycerol, total- and LDL-cholesterol concentrations without any alteration in HDL-cholesterol levels [70-72]. Epidemiological evidence positively correlating garlic consumption with a reduction in the incidence of various types of cancers also abounds $[73,74]$. The finding that garlic powder has no effect on blood cholesterol level has been reasonably attributed to a possible loss of garlic's biologically active components, particularly allicin, during preparation [75]. The presence in crushed garlic of various biologically active (degradation) compounds such as polysulfanes and the vinyldithiins, mean that not all health-promoting activities in crude preparations can be unequivocally ascribed to allicin directly. Our focus here will be restricted to only those health-promoting benefits that have been unequivocally demonstrated to be due to allicin's specific and direct involvement.

\subsection{Allicin and Cardiovascular Diseases}

Cardiovascular disorders are complex, since they are influenced by different factors. Epidemiological studies unearth more and more variables that contribute to the development of cardiovascular problems to different extents [76]. In particular, general oxidative events like the oxidation of the low-density lipid protein (LDL) correlate frequently with atherosclerosis [77]. Although allicin is chemically an oxidant, it acts in lower doses as antioxidant at the physiological level [78]. This observation can be explained by the fact that mild oxidative conditions induce the expression of so-called phase II detoxifying enzymes, for instance by the activation of redox-sensitive transcription factors and build up protection against further and stronger oxidative insults.

One example for the oxidation of a redox-sensitive transcription factor by the electrophile allicin is the Nrf2/Keap1 system that regulates the expression of various anti-oxidative enzymes (among others 
of glutathione-biosynthesis). The fact that allicin can induce the Nrf2/Keap1 system has been shown in various studies $[79,80]$. It needs to be mentioned that the activation of Nrf2 by allicin is not only important in the context of cardiovascular diseases, but also for various other health related events like neurodegenerative diseases. In that context it was shown that allicin attenuates age-related cognitive and memory deficits by activating the Nrf2-system [80].

According to the so-called "LDL-receptor hypothesis" cholesterol is central for atherosclerosis [81], possibly due to the attraction and activation of macrophages by oxidized LDL, subsequently causing plaques in the arteries. Hence, cholesterol is assumed to be a risk-factor for atherosclerosis and thus for ischaemic disorders like Angina pectoris, cardiac infarction or stroke. One strategy, to interfere with a progression of plaque deposition in arteries is the reduction of the endogenous cholesterol-biosynthesis, commonly by application of statins [82]. While statins in the classical way competitively inhibit the enzyme 3-hydroxy-3-methylglutaryl-coenzyme-A-reductase (HMG-CoA reductase), allicin also shows the ability to suppress cholesterol biosynthesis [83,84], which is ascribed to the inhibition of the squalene-monooxygenase [85] and acetyl-CoA synthetase [50] enzymes. Furthermore, because coenzyme A contains a thiol-group, one can assume that allicin reacts with non-acetylated CoA directly, with the consequence that $\mathrm{CoA}$ is not available for biosynthetic processes. This would reduce the biosynthetic rates of CoA-dependent pathways (including sterol-biosynthesis) in a concentration-dependent manner. However, to our knowledge, this thioallylation of CoA has not yet been demonstrated. The different effects of allicin on cholesterol-biosynthesis are summarized in Scheme 4.

Scheme 4. Impact of allicin on cholesterol-metabolism: Allicin was shown to inhibit two important enzymes of the cholesterol-biosynthesis pathway. On the one hand, Gupta and Porter [85] showed that allicin inhibits the squalene-monooxygenase while Focke and coworkers [50] demonstrated an inhibition of acetyl-CoA synthetase, a very early (and thus unspecific) step in cholesterol-biosynthesis. According to its chemistry, one can assume a direct reaction of allicin with the thiol-group of coenzyme A.

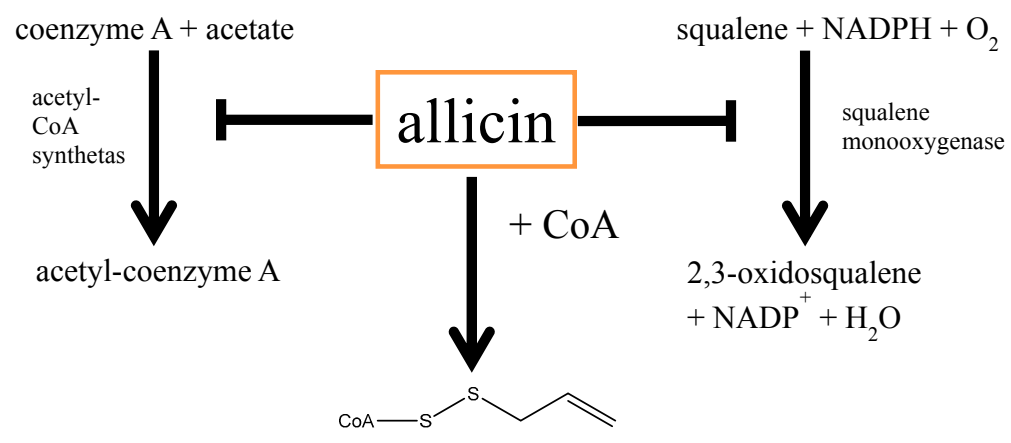

A further important factor of cardiovascular disorders is platelet-aggregation, which is also important for ischemia of the heart and the brain. Platelet-aggregation is a complex biochemical process. Its prerequisite is the activation of the GPIIb/IIIa receptor by thromboxane A2 which causes the binding of, among others, fibrinogen [86]. Classical platelet-aggregation-inhibitors like acetyl-salicylic acid (aspirin) inhibit endogenous thromboxane-biosynthesis and thus the GPIIb/IIIa receptor activation. Interestingly, thiosulfinates like allicin are potent platelet-aggregation inhibitors. While a final concentration of $0.4 \mathrm{mM}$ allicin inhibits platelet aggregation to about $90 \%$, a comparable 
concentration of $0.36 \mathrm{mM}$ aspirin shows less than half this activity ( $35 \%$ inhibition) [87].

A last, but not minor impact of allicin on factors contributing to cardiovascular diseases is hypertension. Allicin acts as an antihypertensive and the reason, again, can be found in allicin's reactivity. Since allicin decomposes rapidly to its degradation products, it has been shown that a complex reaction cascade with thiols (glutathione in particular) results in the release of hydrogen sulfide $\left(\mathrm{H}_{2} \mathrm{~S}\right)[88] \mathrm{H}_{2} \mathrm{~S}$, again, is a known potent gaseous signalling molecule in regard to blood-pressure regulation [89]. $\mathrm{H}_{2} \mathrm{~S}$ lowers the blood pressure by relaxation of smooth-muscle cells surrounding the blood vessel that can expand and thus results in a lower blood pressure [88].

Taken together, it can be concluded that allicin counteracts cardiovascular diseases in various ways. Because of the high epidemiological impact and prevalence of cardiovascular diseases [90] and due to the fact that allicin is a component of fresh garlic in food [4], allicin and its follow-on products are of great interest influencing cardio-vascular disorders. Although, some aspects are already understood, further efforts are necessary to understand in more detail the molecular basis of allicin's action. Epidemiological studies addressing the question how the uptake of allicin (or fresh garlic in its natural form) is beneficial for health would also be important.

\subsection{Allicin's Immune-Modulatory Activity}

Allicin is a strong antimicrobial agent (see above) and is thus, at least in vitro, a potent antibiotic. Besides this direct impact on pathogens, a further facet of its activity is the influence on the endogenous immune system. If allicin is able to affect immune-correlated signalling pathways in cells, new possibilities for therapeutic development might be realized: In the case that allicin stimulates the activity of immune cells, this should result in a strengthened defence against pathogens, and suppression of immune processes might be of interest in regard to allergy or auto-immune disorders. In the meantime a plethora of evidence exists suggesting that allicin indeed acts on various immune-correlated processes.

The initial observation was that allicin inhibits the migration of neutrophilic granulocytes into epithelia, which is a crucial process during inflammation [91]. Anti-inflammatory effects in a general sense have, indeed, been observed, e.g., in the mouse-model of Morbus Bechterew, a degenerative rheumatoid disease of the vertebral body [92]. Furthermore, allicin acts on T-cell lymphocytes by inhibition of the SDF1 $\alpha$-chemokine-induced chemotaxis and this effect is correlated with an impaired dynamic of the actin-cytoskeleton [93]. Finally, it has been shown that allicin inhibits the transendothelial migration of neutrophils (ibid.). It should be mentioned that allicin has been shown to have effects on the cytoskeleton in different biological systems. For example, it has been shown in mouse fibroblasts (NIH-3T3) that allicin causes a depolymerisation of the tubulin-cytoskeleton within minutes at a low concentration $(2 \mu \mathrm{M})$, while with this concentration the actin cytoskeleton remained unaffected [94]. A key player in the activation of lymphocytes is the $\mathrm{p} 21^{\text {ras }}$ protein which triggers the inactivation of the RAS-GTPase by enhancing its enzymatic activity [95]. Interestingly, p $21^{\text {ras }}$ appears to be a direct target of allicin since it seems to be thioallylated by allicin and thus activated [96] and, subsequently, this activation might result in an enhanced phosphorylation of the ERK1/2 kinase (ibid.), an important MAP-kinase involved in different signalling pathways (Scheme 5). 
Scheme 5. Allicin stimulates lymphocytes by affecting $\mathrm{p} 21^{\text {ras. }}$ : Thioallylation that means the binding of an allyl sulfenic acid to the thiol of cysteine ${ }^{118}$ leads to an activation of $\mathrm{p} 21^{\text {ras }}$ and subsequently to stimulation of ERK1/2 phosphorylation. These processes are crucial for the activation of lymphocytes.

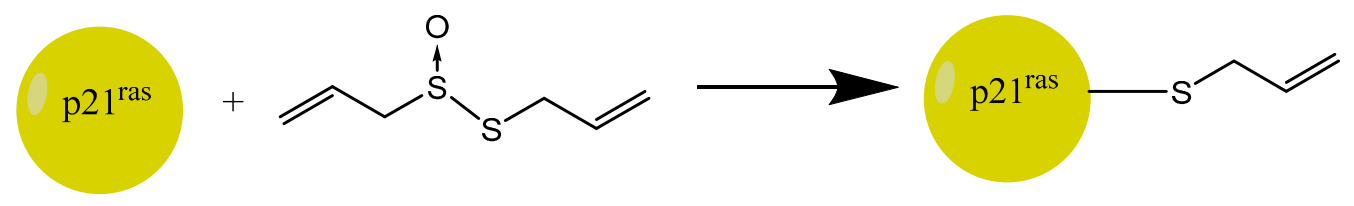

Another central regulator of a coordinated immune-response is the TNF $\alpha$ cytokine [97]. Impairment of TNF $\alpha$ secretion massively influences the regulation of the immune-response. For that reason it is interesting that allicin inhibits the release of TNF $\alpha$-dependent pro-inflammatory cytokines in intestinal epithelia [98]. This, however, reflects an effect of allicin on factors downstream of TNF $\alpha$. Since TNF $\alpha$ is mainly secreted by macrophages [99], the effect of allicin on macrophages was examined with respect to how allicin influences the expression of TNFa itself. It is interesting that a stimulation of macrophages by lipopolysaccharide (LPS) after a pre-incubation in the presence of allicin enhances the activity of the TNF $\alpha$ promoter, suggesting a TNF $\alpha$-triggering role for allicin in LPS-stimulated cells [100]. Furthermore, allicin inhibits phosphatase-activity, correlating with an enhanced phosphorylation of ERK1/2 (ibid.), which is a central component of the signalling cascade transferring extracellular signals into intracellular signalling cascades. Furthermore, the release of Reactive Nitrogen Species (RNS) by LPS-stimulated macrophages was suppressed by allicin [100,101].

It is fascinating if allicin could influence inflammation both directly by exerting an antimicrobial effect and by altering immune-cell signalling. It will be informative to study further the effects of allicin on immune cells on a molecular level and, systematically, it's impact on the development of inflammatory processes and disease.

\subsection{Allicin and Cancer}

There is a link between the functioning of the immune system and cancer. In an early study (1960), explants of mouse-tumours were incubated in allicin before implantation into healthy mice. In contrast to the control group (where the explants were not allicin-treated), mice with tumour explants incubated in allicin showed no further growth of the explant [102].

How allicin affects cancer cells has been examined at the molecular level. It became clear that the induction of apoptosis was crucial for the anti-cancer effect of allicin. As discussed in the yeast system (see above), allicin also causes a redox-shift in human cell cultures [103]. This leads to the execution of cell death, both in a caspase-dependent [104] and caspase-independent manner [105]. Beside caspase activity, the apoptosis inducing factor (AIF), which contributes to the apoptotic DNA-laddering, is involved in allicin-induced cell death ( $\mathrm{ibid}$.).

Bat-Chen and co-workers, for instance, showed that Nrf2 is involved in allicin-induced apoptosis [106]. This reveals the "Janus face" of Nrf2 [107]: While Nrf2 is mostly described as an anti-apoptotic factor regulating the expression of anti-apoptotic proteins of the Bcl-2 family like Bcl-2 and Bcl-xL [108,109], Nrf2 also seems to have a pro-apoptotic function under certain circumstances 
(ibid.). Also the ERK1/2 map kinases were shown to be influenced by allicin in immune cells; these kinases are also important for apoptosis induction by allicin [103,110].

Although this paragraph gives only a brief overview about the impact of allicin on cancer cells, some major factors targeted by allicin can be outlined. One problem exacerbating a clinical application of allicin is its chemical instability. As soon allicin is taken up by the body, or at the latest in the circulatory system, it will react with accessible thiols and in particular with the high amount of glutathione and also be decomposed to other compounds. This makes an application as a pharmaceutical at the moment unlikely. However, the potential for using garlic in a nutriceutical context, with health benefits not only for cancer prevention or therapy, but also for the other medical areas mentioned here, remains an attractive possibility. A sophisticated attempt to circumvent the stability problem is a coupling of alliinase to a delivery system and supplying the stable substrate alliin, thus allowing production of allicin in situ at the position of the particular epitope. In this regard, attaching alliinase via antibodies against cancer cells successfully showed a promising proof-of principle [111].

\section{Effects of Allicin on Plants}

\section{Effects on Germination, Root Growth and Viability on Arabidopsis thaliana}

Having already discussed allicin's effects on bacteria, fungi and animal systems in this review it remains to comment on the effects of allicin on plant physiology. In our lab we investigated the effects of allicin treatment on different developmental stages of the model plant Arabidopsis thaliana. The effect of increasing allicin concentrations on the development of Arabidopsis (accession Col-0) seedlings was monitored.

Two morphological effects could be seen by the naked eye (Figure 3). Firstly, exposure to allicin correlated with a decrease in primary root elongation in a concentration-dependent manner and the minimal allicin concentration needed to inhibit root elongation completely was determined to be $75 \mu \mathrm{M}$ allicin (Figure 4). The fact that the root growth is inhibited by allicin without killing the whole plant indicates that root functions like the uptake of water and nutrients are presumably still operational.

Secondly, exposure to a much higher concentration (500 $\mu \mathrm{M}$ allicin) led to bleaching of the seedlings (Figure 5).

Because allicin is an efficient thiol reagent, we reasoned that a plant with reduced amounts of GSH should be more severely affected in the inhibition of seed germination and primary root growth than wild type (wt) plants. Therefore, we tested the A. thaliana phytoalexin deficient 2-1 (pad2-1) mutant (Col-0 background), which only has approximately $20 \%$ of normal GSH levels due to a mutation in the gene coding for the enzyme glutamate cysteine ligase (GCL, Figure 6A) [112]. Seed-germination of the pad2-1 mutant was found to be approximately $3 \times$ more sensitive to allicin than the wt and primary root growth was also inhibited at lower allicin concentrations than in the wt (data not shown). The greater sensitivity of the GSH-deficient pad2-1 mutant is in accordance with earlier studies of in vitro enzyme inhibition by allicin $[51,52,113]$. Enzyme inhibition by allicin could be competed out by incorporation of cysteine or GSH into the reaction buffer and post-incubation with GSH led to a reversal of the inhibition for most (but not all) enzymes (ibid.). Although the enzyme inhibition studies were done in vitro, GSH is the most important and most abundant redox buffer in vivo in most 
eucaryotic and procaryotic cells [67], lending support to the idea that GSH is a protective agent against allicin in vivo.

Figure 3. Effect of allicin on seedling development: A. thaliana (Col-0) wild type $48 \mathrm{~h}$ after allicin treatment. In this experiment, seeds were set on sterile filter papers which were placed on Murashige \& Skoog (MS) medium. After stratification at $4{ }^{\circ} \mathrm{C}$ for $48 \mathrm{~h}$, germination and growth took place with the Petri plates tilted to an angle of approx. $20^{\circ}$ from vertical to ensure unidirectional root growth according to root gravitropism. After three days of cultivation, filter papers were transferred to MS media that contained different amounts of allicin. Pictures were taken $48 \mathrm{~h}$ after treatment. For the sake of clarity only a small representative fraction of seedlings is shown for relevant concentrations.

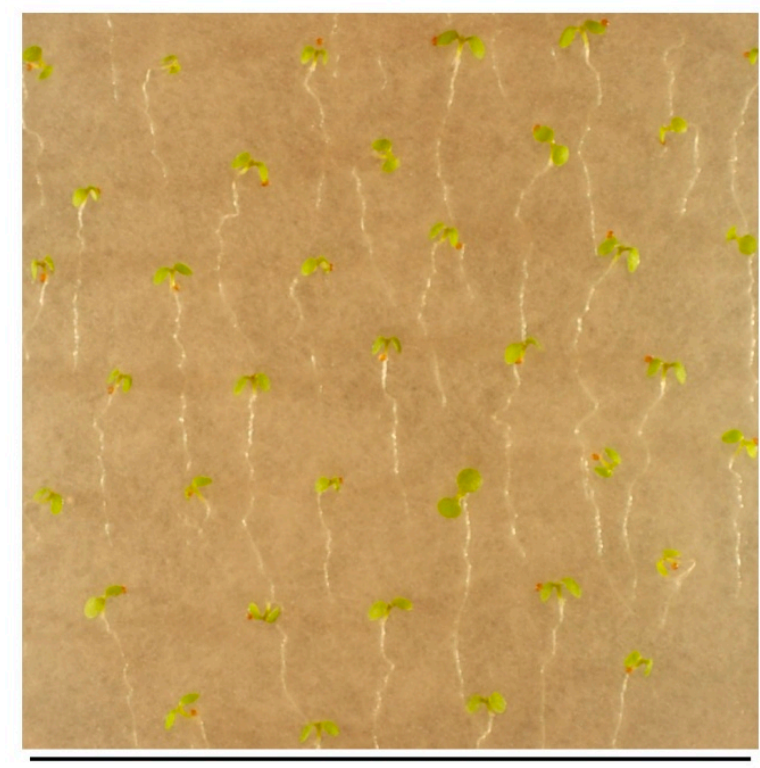

$0 \mu \mathrm{M}$ allicin

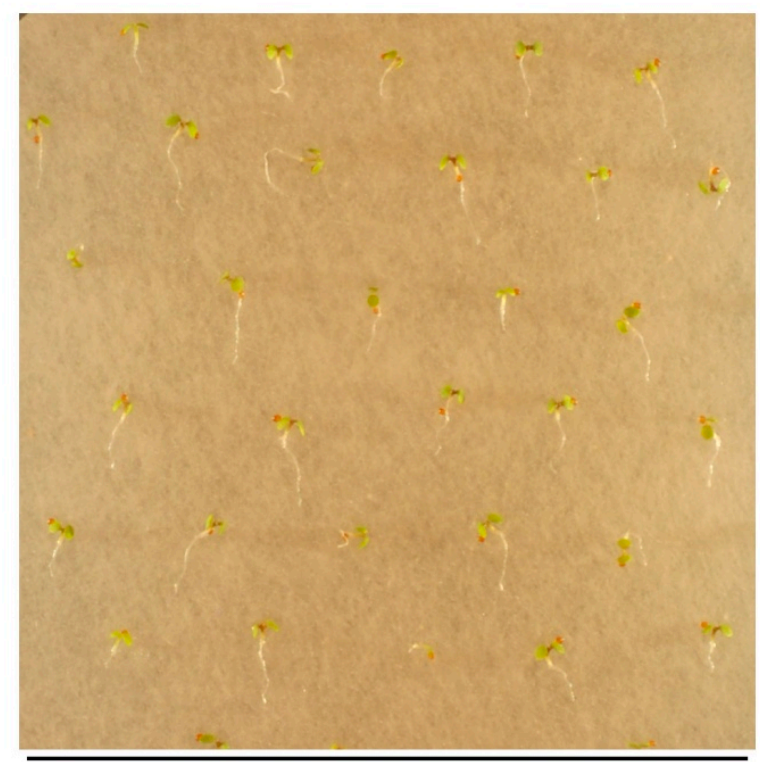

$75 \mu \mathrm{M}$ allicin

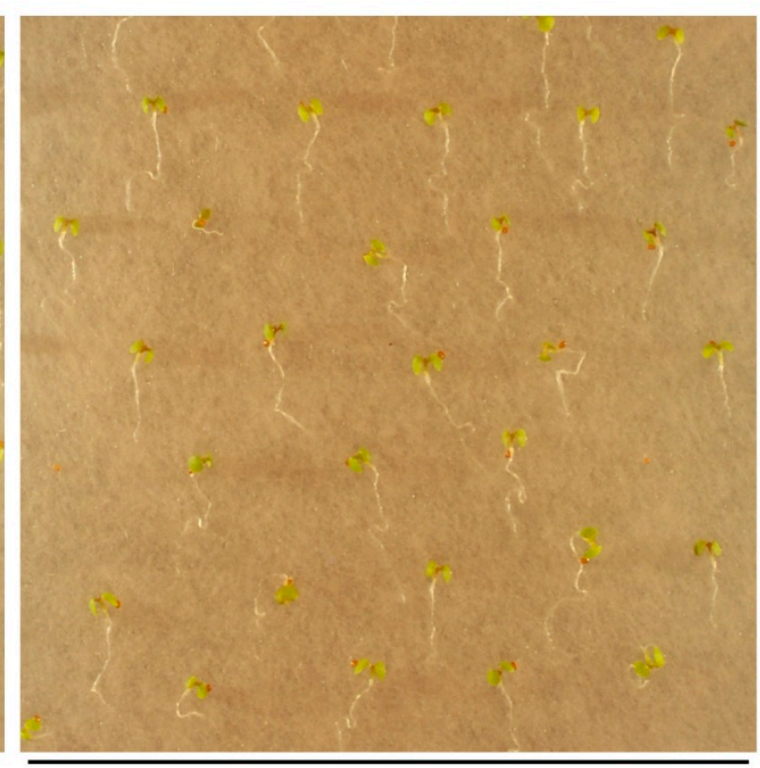

$50 \mu \mathrm{M}$ allicin

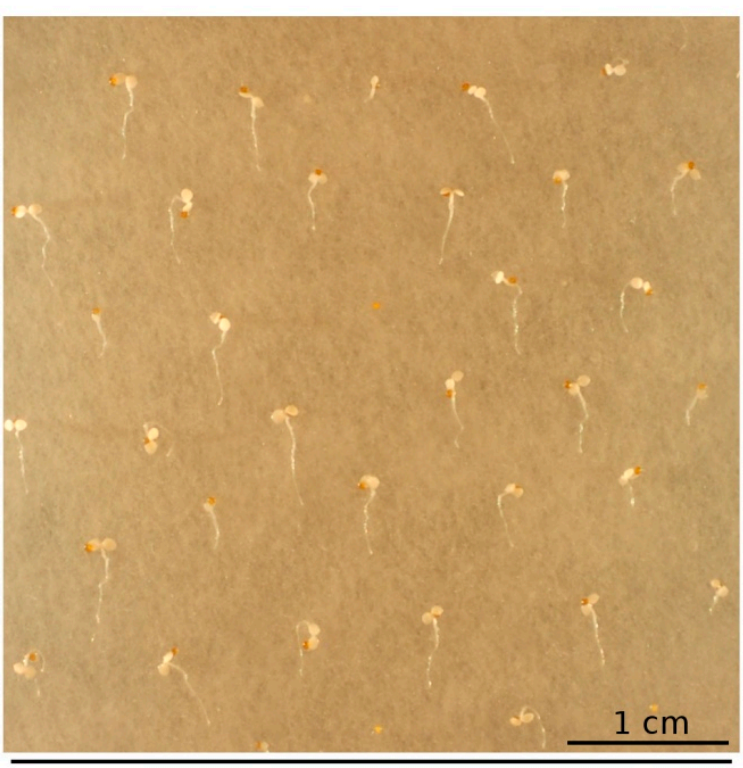

$1000 \mu \mathrm{M}$ allicin 
Figure 4. Effect of allicin on elongation of primary root growth: To investigate the effects of allicin on A. thaliana seedlings (accession Col-0), seeds were sown onto sterile filter paper which had been placed on Murashige \& Skoog (MS) medium beforehand. After stratification $\left(4{ }^{\circ} \mathrm{C}, 48 \mathrm{~h}\right)$, the Petri plates were cultivated at an angle approx. $20^{\circ}$ from vertical to ensure unidirectional gravitropic root growth. For allicin exposure, the filter papers were transferred onto allicin-containing medium and $48 \mathrm{~h}$ after further cultivation, pictures were taken and the root lengths were measured using the software ImageJ [114]. The "boxplot" was prepared with the program PAST [115]; every dot represents the measurement of one root. The two halves of one box represent the 25 and 75 percent quartile, while the horizontal line in the middle shows the median. $\mathrm{n}=$ total number of measurements for the given treatment.

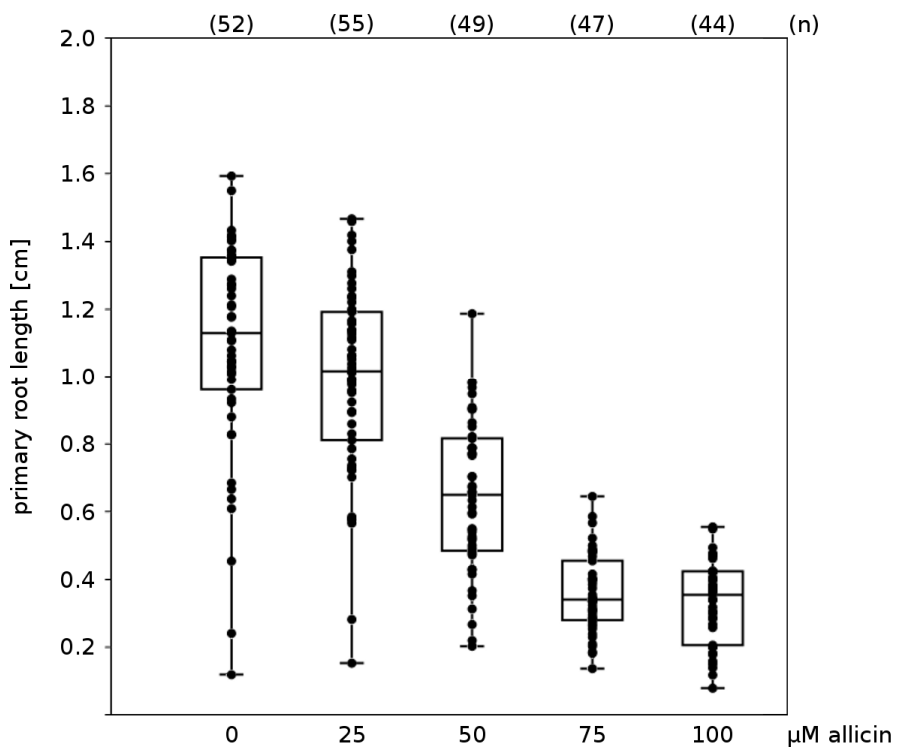

Figure 5. Allicin causes bleaching of seedlings: Sterile filter papers were placed on Murashige \& Skoog (MS) medium and were sown with Col-0 A. thaliana wild type seeds. Following stratification $\left(4{ }^{\circ} \mathrm{C}, 48 \mathrm{~h}\right)$, seeds were allowed to germinate and grow for three days. For allicin treatment, the filter papers were transferred onto MS medium containing different amounts of allicin. Effects on the seedlings were recorded $48 \mathrm{~h}$ after allicin treatment. Bleached seedlings showed either partial or complete bleaching, whereas green seedlings showed no signs of bleaching.

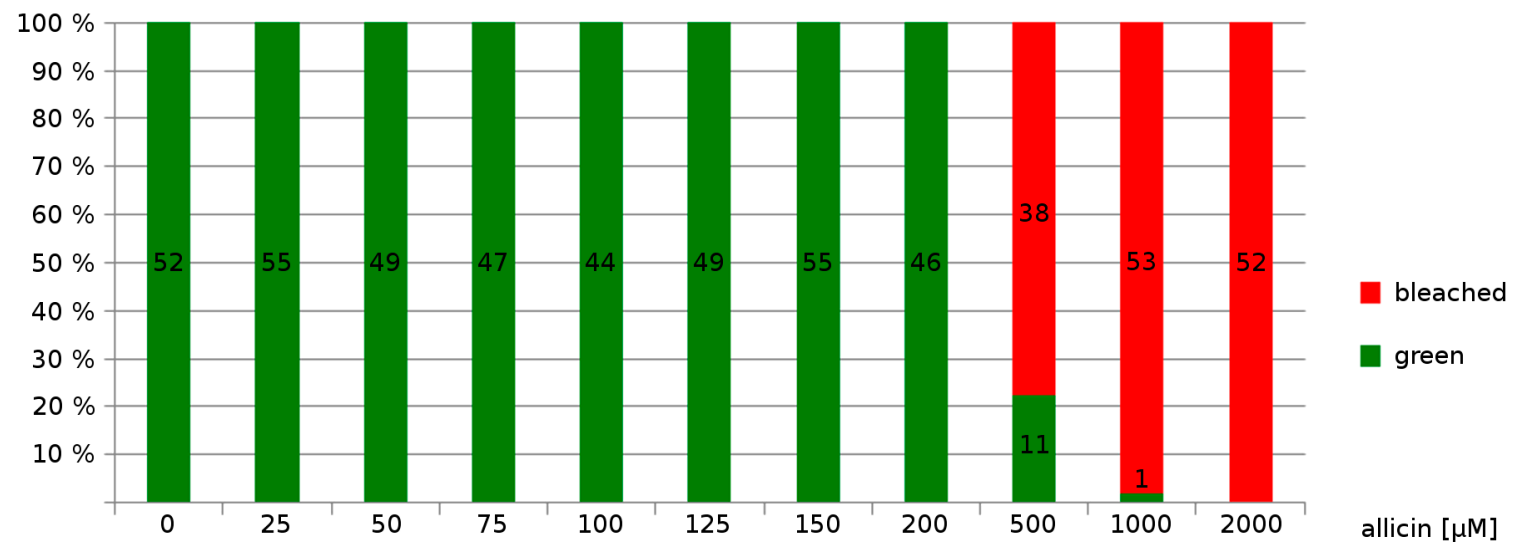


Besides the fact that GSH can reduce disulfides back to thiols (Scheme 3), glutathiolation of accessible thiol groups can protect against their over-oxidation to sulfinic and sulfonic acids [23] (Figure 6B). As already discussed above, GSH is known to buffer the redox state of the cell [67]. Since it has been demonstrated that allicin also can shift the cell's redox potential by oxidizing the glutathione pool, and push cells into apoptosis [68], the importance of GSH levels in cellular protection against allicin becomes doubly clear.

Figure 6. Glutathione biosynthesis and function: (A) Cysteine and glutamate are enzymatically linked to $\gamma$-glutamylcysteine via the action of glutamate cysteine ligase (GCL). The next step in synthesis is the formation of glutathione itself from cysteine and $\gamma$-glutamylcysteine via glutathione synthetase (GS). (B) Glutathione can be oxidized to glutathione dimers (GSSG) and thereby serves to buffer oxidants within the cell. A shift in the equilibrium from GSH towards a higher proportion of GSSG may promote the glutathiolation of free cysteines on protein surfaces, thus shielding these cysteine residues during oxidative stress conditions from over-oxidation. Illustration was redrawn from [116].

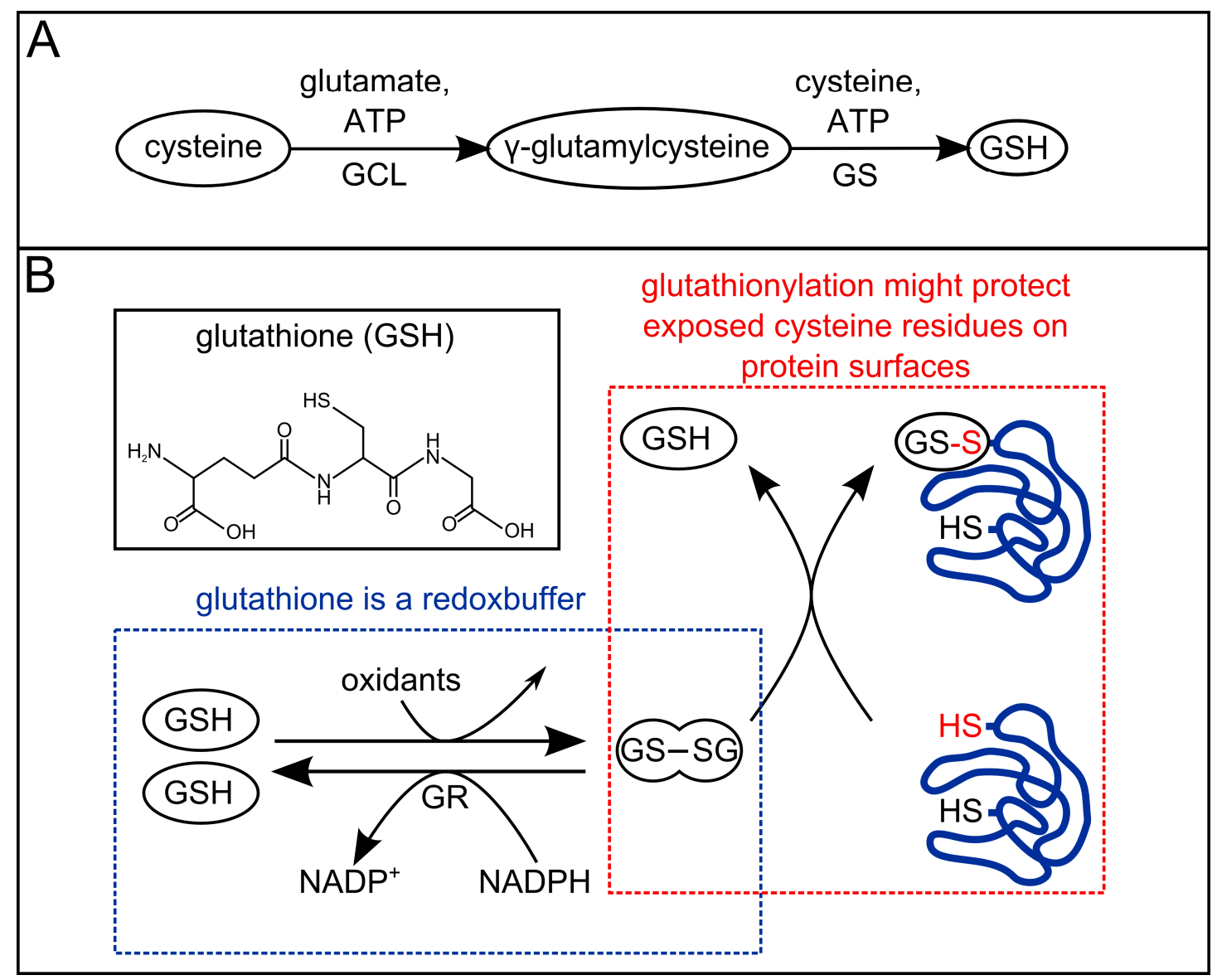

\section{Conclusions}

Allicin is a natural product which is consumed widely in most cultures that employ garlic in their diet. It is a physiologically active molecule with many potential health benefits. Furthermore, its potential for development in human and veterinary medicine is great and the concept of farmers being able to "grow their own" plant protection in an environmentally friendly manner is attractive, 
particularly in subsistence agriculture where the cost of commercial preparations may be prohibitive. This review, hopefully, will help to bring some of the scientific literature on the effects of allicin to the attention of interested scientists who may then further contribute to our understanding of this fascinating molecule.

\section{Acknowledgments}

J.B., F.A., M.G. and A.J.S. gratefully acknowledge financial support from RFwN and RWTH Aachen University, I.D.N. gratefully acknowledges financial support from Rotimi Aluko's NSERC Discovery Grant as well as the University of Manitoba's Graduate Enhancement of Tri-Council Stipends (GETS) program.

\section{Author Contributions}

J.B. contributed unpublished novel results in the section on effects of allicin on plants, all authors worked equally on the preparation and editing of the MS and are thus otherwise arranged alphabetically.

\section{Conflicts of Interest}

The authors declare no conflict of interests.

\section{References}

1. Slusarenko, A.J.; Patel, A.; Portz, D. Control of plant diseases by natural products: Allicin from garlic as a case study. Eur. J. Plant Pathol. 2008, 121, 313-322.

2. Rishton, G.M. Natural products as a robust source of new drugs and drug leads: Past successes and present day issues. Am. J. Cardiol. 2008, 101, 43-49.

3. Newman, D.J.; Cragg, G.M.; Snader, K.M. The influence of natural products upon drug discovery (Antiquity to late 1999). Nat. Prod. Rep. 2000, 17, 215-234.

4. Block, E. Garlic and Other Alliums-The Lore and The Science; RSC publishing: Cambridge, UK, 2010.

5. Koch, H.P.; Lawson, L.D. Garlic: The Science and Therapeutic Application of Allium sativum L. and Related Species; Williams \& Wilkins: Baltimore, MD, USA, 1996.

6. Castiglioni, A. A History of Medicine; Jason Aronson Inc.: New York, NY, USA, 1978.

7. Brewster, J.L. Onions and Other Vegetable Alliums; CABI Publishing: Wallingford, UK, 2008.

8. Rabinowitch, H.D.; Currah, L. Allium Crop Science: Recent Advances; CABI Publishing: Wallingford, UK, 2002.

9. Cavallito, C.; Bailey, J. Allicin, the antibacterial principle of Allium sativum. I. Isolation, physical properties and antibacterial action. J. Am. Chem. Soc. 1944, 66, 1950-1951.

10. Josling, P. Allicin-The Heart of Garlic; NWI Publishing: Callahan Florida, FL, USA, 2007.

11. Stoll, A.; Seebeck, E. Über Alliin, die genuine Muttersubstanz des Knoblauchöls. Helv. Chim. Acta 1948, 31, 189-210.

12. Cavallito, C.; Bailey, J.; Buck, J. The antibacterial principle of Allium sativum. III. Its precursor and "essential oil of garlic". J. Am. Chem. Soc. 1945, 67, 1032-1033. 
13. Granroth, B. Biosynthesis and decomposition of cysteine derivatives in onion and other Allium species. Ann. Acad. Sci. Fenn. Chem. 1970, 154, 4-71.

14. Stoll, A.; Seebeck, E. Über die Spezifität der Alliinase und die Synthese mehrerer dem Alliin verwandter Verbindungen. Helv. Chim. Acta 1949, 32, 866-876.

15. Ilić, D.; Nikolić, V.; Nikolić, L.; Stanković, M.; Stanojević, L.; Cakić, M. Allicin and related compounds: Biosynthesis, synthesis and pharmacological activity. Facta Univ. Phys. Chem. Technol. 2011, 9, 9-20.

16. Virtanen, A.I.; Matikkala, E.J. The Isolation of S-methylcysteinesulphoxide and S- $n$-propenylcysteinesulphoxide from onion (Allium cepa) and the antibiotic activity of crushed onion. Acta Chem. Scand. 1959, 13, 1898-1900.

17. Stoll, A.; Seebeck, E. Über Alliin, die genuine Muttersubstanz des Knoblauchöls. Experientia 1947, 3, 114-115.

18. Cruz-Villalon, G. Synthesis of allicin and purification by solid-phase extraction. Anal. Biochem. 2001, 290, 376-378.

19. Vaidya, V.; Ingold, K.U.; Pratt, D. A garlic: Source of the ultimate antioxidants-sulfenic acids. Angew. Chem. Int. Ed. Engl. 2009, 48, 157-160.

20. Miron, T.; Bercovici, T.; Rabinkov, A.; Wilchek, M.; Mirelman, D. $\left[{ }^{3} \mathrm{H}\right]$ Allicin: Preparation and applications. Anal. Biochem. 2004, 331, 364-369.

21. Fry, F.H.; Okarter, N.; Baynton-Smith, C.; Kershaw, M.J.; Talbot, N.J.; Jacob, C. Use of a substrate/alliinase combination to generate antifungal activity in situ. J. Agric. Food Chem. 2005, 53, 574-580.

22. Freeman, F.; Kodera, Y. Garlic chemistry: Stability of S-(2-propenyl)-2-propene-1-sulfinothioate (allicin) in blood, solvents, and simulated physiological fluids. J. Agric. Food Chem. 1995, 43, 2332-2338.

23. Gruhlke, M.C.H.; Slusarenko, A.J. The biology of reactive sulfur species (RSS). Plant Physiol. Biochem. 2012, 59, 98-107.

24. Gruhlke, M.; Slusarenko, A.J. The Cellular "Thiolstat" as an Emerging Potential Target of Some Secondary Metabolites. In Recent Advances in Redox Active Plant and Microbial Products; Jacob, C., Ed.; Springer: Dordrecht, The Netherlands, 2014.

25. Nagy, P. Kinetics and mechanisms of thiol-disulfide exchange covering direct substitution and thiol oxidation-mediated pathways. Antioxid. Redox Signal. 2013, 18, 1023-1041.

26. Morgan, B.; Ezerina, D.; Amoako, T. Multiple glutathione disulfide removal pathways mediate cytosolic redox homeostasis. Nat. Chem. Biol. 2012, 9, 119-125.

27. De Rey-Pailhade, J. Sur un corps d'origine organique hydrogenant le soufre a froid. CR Acad. Sci. 1888, 106, 1683-1684.

28. Hopkins, F. On an autoxidisable constituent of the cell. Biochem. J. 1921, 15, 286-305.

29. Harington, C.; Mead, T. Synthesis of glutathione. Biochem. J. 1935, 29, 1602-1611.

30. Conn, E.; Vennesland, B. Glutathione reductase of wheat germ. J. Biol. Chem. 1951, 192, 17-28.

31. Conn, E.; Vennesland, B. Enzymatic reduction of glutathione by triphosphopyridine nucleotide (co-enzyme II). Nature 1951, 167, 976-977. 
32. Grant, C.M.; Collinson, L.P.; Roe, J.H.; Dawes, I.W. Yeast glutathione reductase is required for protection against oxidative stress and is a target gene for YAP-1 transcriptional regulation. Mol. Microbiol. 1996, 21, 171-179.

33. Muller, E.G. A glutathione reductase mutant of yeast accumulates high levels of oxidized glutathione and requires thioredoxin for growth. Mol. Biol. Cell 1996, 7, 1805-1813.

34. Tada, Y.; Spoel, S.H.; Pajerowska-Mukhtar, K.; Mou, Z.; Song, J.; Wang, C.; Zuo, J.; Dong, X. Plant immunity requires conformational changes [corrected] of NPR1 via S-nitrosylation and thioredoxins. Science 2008, 321, 952-956.

35. Kuge, S.; Arita, M.; Murayama, A. Regulation of the yeast Yap1p nuclear export signal is mediated by redox signal-induced reversible disulfide bond formation. Mol. Cell. Biol. 2001, 21, 6139-6150.

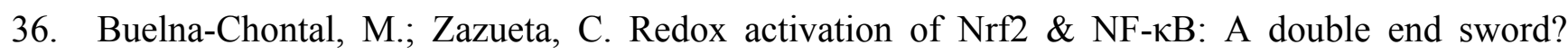
Cell Signal. 2013, 25, 2548-2557.

37. Pasteur, L. Memoire sur la fermentation appelee lactique. Mem. Soc. Imp. Sci. Agric. Lille 1858, $5,13-26$.

38. Small, L.D.; Bailey, J.H.; Cavallito, C.J. Alkyl Thiosulfinates. J. Am. Chem. Soc. 1947, 69, 1710-1713.

39. Curtis, H.; Noll, U.; Störmann, J.; Slusarenko, A.J. Broad-spectrum activity of the volatile phytoanticipin allicin in extracts of garlic (Allium sativum L.) against plant pathogenic bacteria, fungi and Oomycetes. Physiol. Mol. Plant Pathol. 2004, 65, 79-89.

40. Fujisawa, H.; Watanabe, K.; Suma, K.; Origuchi, K.; Matsufuji, H.; Seki, T.; Ariga, T. Antibacterial potential of garlic-derived allicin and its cancellation by sulfhydryl compounds. Biosci. Biotechnol. Biochem. 2009, 73, 1948-1955.

41. Cutler, R.R.; Wilson, P. Antibacterial activity of a new, stable, aqueous extract of allicin against methicillin-resistant Staphylococcus aureus. Br. J. Biomed. Sci. 2004, 61, 71-74.

42. Cañizares, P.; Gracia, I.; Gómez, L.A.; García, A.; de Argila, C.M.; Boixeda, D.; de Rafael, L. Thermal degradation of allicin in garlic extracts and its implication on the inhibition of the in vitro growth of helicobacter pylori. Biotechnol. Prog. 2004, 20, 32-37.

43. Hughes, B.; Lawson, L. Antimicrobial effects of Allium sativum L. (garlic), Allium ampeloprasum L. (elephant garlic), and Allium cepa L. (onion), garlic compounds and commercial garlic supplement products. Phyther. Res. 1991, 5, 154-158.

44. De Lancey Pulcini, E. Bacterial biofilms: A review of current research. Nephrologie 2001, 22, 439-441.

45. Miron, T.; Rabinkov, A.; Mirelman, D.; Wilchek, M.; Weiner, L. The mode of action of allicin: Its ready permeability through phospholipid membranes may contribute to its biological activity. Biochim. Biophys. Acta Biomembr. 2000, 1463, 20-30.

46. Feldberg, R.; Chang, S. In vitro mechanism of inhibition of bacterial cell growth by allicin. Antimicrob. Agents Chemother. 1988, 32, 1763-1768.

47. Cavallito, C.J.; Bailey, J.H. Preliminary note on the inactivation of antibiotics. Science 1944, 100, 390-390.

48. Cavallito, C.J. Relationship of thiol structures to reaction with antibiotics. J. Biol. Chem. 1946, $164,29-34$. 
49. Roos, G.; Foloppe, N.; Messens, J. Understanding the $\mathrm{pK}_{\mathrm{a}}$ of redox cysteines: The key role of hydrogen bonding. Antioxid. Redox Signal. 2013, 18, 94-127.

50. Focke, M.; Feld, A.; Lichtenthaler, H.K. Allicin, a naturally occurring antibiotic from garlic, specifically inhibits acetyl-CoA synthetase. FEBS Lett. 1990, 261, 106-108.

51. Rabinkov, A.; Miron, T.; Konstantinovski, L.; Wilchek, M.; Mirelman, D.; Weiner, L. The mode of action of allicin: Trapping of radicals and interaction with thiol containing proteins. Biochim. Biophys. Acta 1998, 1379, 233-244.

52. Wills, E.D. Enzyme inhibition by allicin, the active principle of garlic. Biochem. J. 1956, 63, 514-520.

53. Van Etten, H.D.; Mansfield, J.W.; Bailey, J.A.; Farmer, E.E. Two classes of plant antibiotics: Phytoalexins versus "phytoanticipins". Plant Cell 1994, 6, 1191-1192.

54. Auger, J.; Arnault, I.; Diwo-Allain, S.; Ravier, N.; Molia, F.; Pettiti, M. Insecticidal and fungicidal potential of Allium substances as biofumigants. Agroindustria 2004, 3, 5-8.

55. Khodavandi, A.; Alizadeh, F.; Harmal, N.S.; Sidik, S.M.; Othman, F.; Sekawi, Z.; Jahromi, M.A.F.; Ng, K.P.; Chong, P.P. Comparison between efficacy of allicin and fluconazole against Candida albicans in vitro and in a systemic candidiasis mouse model. FEMS Microbiol. Lett. 2011, 315, 87-93.

56. Perelló, A.; Gruhlke, M.; Slusarenko, A.J. Effect of garlic extract on seed germination, seedling health, and vigour of pathogen-infested wheat. J. Plant Prot. Res. 2013, 53, 317-323.

57. Yamada, Y.; Azuma, K. Evaluation of the in vitro antifungal activity of allicin. Antimicrob. Agents Chemother. 1977, 11, 743-749.

58. Shadkchan, Y.; Shemesh, E.; Mirelman, D.; Miron, T.; Rabinkov, A.; Wilchek, M.; Osherov, N. Efficacy of allicin, the reactive molecule of garlic, in inhibiting Aspergillus spp. in vitro, and in a murine model of disseminated aspergillosis. J. Antimicrob. Chemother. 2004, 53, 832-836.

59. Ogita, A.; Hirooka, K.; Yamamoto, Y.; Tsutsui, N.; Fujita, K.-I.; Taniguchi, M.; Tanaka, T. Synergistic fungicidal activity of $\mathrm{Cu}^{2+}$ and allicin, an allyl sulfur compound from garlic, and its relation to the role of alkyl hydroperoxide reductase 1 as a cell surface defense in Saccharomyces cerevisiae. Toxicology 2005, 215, 205-213.

60. Ogita, A.; Fujita, K.-I.; Taniguchi, M.; Tanaka, T. Dependence of synergistic fungicidal activity of $\mathrm{Cu}^{2+}$ and allicin, an allyl sulfur compound from garlic, on selective accumulation of the ion in the plasma membrane fraction via allicin-mediated phospholipid peroxidation. Planta Med. 2006, $72,875-880$.

61. Ogita, A.; Fujita, K.; Taniguchi, M.; Tanaka, T. Enhancement of the fungicidal activity of amphotericin B by allicin, an allyl-sulfur compound from garlic, against the yeast Saccharomyces cerevisiae as a model system. Planta Med. 2006, 72, 1247-1250.

62. Ogita, A.; Fujita, K.; Tanaka, T. Enhancement of the fungicidal activity of amphotericin B by allicin: Effects on intracellular ergosterol trafficking. Planta Med. 2009, 75, 222-226.

63. Kim, Y.-S.; Kim, K.S.; Han, I.; Kim, M.-H.; Jung, M.H.; Park, H.K. Quantitative and qualitative analysis of the antifungal activity of allicin alone and in combination with antifungal drugs. PLoS One 2012, 7, e38242. 
64. Ogita, A.; Nagao, Y.; Fujita, K.-I.; Tanaka, T. Amplification of vacuole-targeting fungicidal activity of antibacterial antibiotic polymyxin B by allicin, an allyl sulfur compound from garlic. J. Antibiot. (Tokyo) 2007, 60, 511-518.

65. Ogita, A.; Yutani, M.; Fujita, K.; Tanaka, T. Dependence of vacuole disruption and indipendence of potassium ion efflux in fungicidal activity induced by combination of amphotericin $\mathrm{B}$ and allicin against Saccharomyces cerevisiae. J. Antibiot. (Tokyo) 2010, 63, 689-692.

66. Carmona-Gutierrez, D.; Eisenberg, T.; Büttner, S.; Meisinger, C.; Kroemer, G.; Madeo, F. Apoptosis in yeast: Triggers, pathways, subroutines. Cell Death Differ. 2010, 17, 763-773.

67. Schafer, F.Q.; Buettner, G.R. Redox environment of the cell as viewed through the redox state of the glutathione disulfide/glutathione couple. Free Radic. Biol. Med. 2001, 30, 1191-1212.

68. Gruhlke, M.C.H.; Portz, D.; Stitz, M.; Anwar, A.; Schneider, T.; Jacob, C.; Schlaich, N.L.; Slusarenko, A.J. Allicin disrupts the cell's electrochemical potential and induces apoptosis in yeast. Free Radic. Biol. Med. 2010, 49, 1916-1924.

69. Yu, L.; Guo, N.; Meng, R.; Liu, B.; Tang, X.; Jin, J.; Cui, Y.; Deng, X. Allicin-induced global gene expression profile of Saccharomyces cerevisiae. Appl. Microbiol. Biotechnol. 2010, 88, 219-229.

70. Kleijnen, J.; Knipschild, P.; ter Riet, G. Garlic, onions and cardiovascular risk factors. A review of the evidence from human experiments with emphasis on commercially available preparations. Br. J. Clin. Pharmacol. 1989, 28, 535-544.

71. Ried, K.; Toben, C.; Fakler, P. Effect of garlic on serum lipids: An updated meta-analysis. Nutr. Rev. 2013, 71, 282-299.

72. Warshafsky, S.; Kamer, R.S.; Sivak, S.L. Effect of garlic on total serum cholesterol. A meta-analysis. Ann. Intern. Med. 1993, 119, 599-605.

73. Kris-Etherton, P.M.; Hecker, K.D.; Bonanome, A.; Coval, S.M.; Binkoski, A.E.; Hilpert, K.F.; Griel, A.E.; Etherton, T.D. Bioactive compounds in foods: Their role in the prevention of cardiovascular disease and cancer. Am. J. Med. 2002, 113, 71-88.

74. Ngo, S.N.T.; Williams, D.B.; Cobiac, L.; Head, R.J. Does garlic reduce risk of colorectal cancer? A systematic review. J. Nutr. 2007, 137, 2264-2269.

75. Isaacsohn, J.L.; Moser, M.; Stein, E.A.; Dudley, K.; Davey, J.A.; Liskov, E.; Black, H.R. Garlic powder and plasma lipids and lipoproteins: A multicenter, randomized, placebo-controlled trial. Arch. Intern. Med. 1998, 158, 1189-1194.

76. Rahman, K.; Lowe, G. Garlic and cardiovascular disease: A critical review. J. Nutr. 2006, 136, 736-740.

77. Kita, T.; Kume, N.; Minami, M.; Hayashida, K.; Murayama, T.; Sano, H.; Moriwaki, H.; Kataoka, H.; Nishi, E.; Horiuchi, H.; et al. Role of oxidized LDL in atherosclerosis. Ann. N. Y. Acad. Sci. 2001, 947, 199-206.

78. Gruhlke, M.C.H.; Nwachukwu, I.; Arbach, M.; Anwar, A.; Noll, U.; Slusarenko, A.J. Allicin from garlic, effective in controlling several plant diseases, ia a reactive sulfur species (RSS) that pushes cells into apoptosis. In Modern Fungicides and Antifungal Compounds VI; DPG Publishers: Braunschweig, Gemany, 2011; pp. 325-334. 
79. Li, X.H.; Li, C.Y.; Xiang, Z.G.; Hu, J.J.; Lu, J.M.; Tian, R.B.; Jia, W. Allicin ameliorates cardiac hypertrophy and fibrosis trought enhancing of $\mathrm{Nrf} 2$ antioxidant signaling pathways. Cardiovasc. Drugs Ther. 2012, 26, 457-465.

80. Li, X.-H.; Li, C.-Y.; Lu, J.-M.; Tian, R.-B.; Wei, J. Allicin ameliorates cognitive deficites ageing-induced learning and memory deficites trought enhancing of Nrf2 antioxidant signaling pathways. Neurosci. Lett. 2012, 514, 46-50.

81. Brown, M.S.; Goldstein, J.L. How LDL receptors influence colesterol and arterosclerosis. Sci. Am. 1984, 251, 58-66.

82. Grobbee, D.E.; Bots, M.L. Statin treatment and progression of artherosclerotic plaque burden. Drugs 2003, 63, 893-911.

83. Eilat, S.; Oestraicher, Y.; Rabinkov, A.; Ohad, D.; Mirelman, D.; Battler, A.; Eldar, M.; Vered, Z. Alteration of lipid profile in hyperlipidemic rabbits by allicin, an active constituent of garlic. Coron. Arter. Dis. 1995, 6, 985-990.

84. Gebhardt, R.; Beck, H.; Wagner, K.G. Inhibition of cholesterol biosynthesis by allicin and ajoene in rat hepatocytes and HepG2 cells. Biochim. Biophys. Acta 1994, 1213, 57-62.

85. Gupta, N.; Porter, T. Garlic and garlic-derived compounds inhibit human squalene monooxygenase. J. Nutr. 2001, 131, 1662-1667.

86. Yip, J.; Shen, Y.; Berndt, M.C.; Andrews, R.K. Primary platelet adhesion receptors. IUBMB Life 2005, 57, 103-108.

87. Briggs, W.H.; Xiao, H.; Parkin, K.L.; Shen, C.; Goldman, I.L. Differential inhibition of human platelet aggregation by selected Allium thiosulfinates. J. Agric. Food Chem. 2000, 48, 5731-5735.

88. Benavides, G.A; Squadrito, G.L.; Mills, R.W.; Patel, H.D.; Isbell, T.S.; Patel, R.P.; Darley-Usmar, V.M.; Doeller, J.E.; Kraus, D.W. Hydrogen sulfide mediates the vasoactivity of garlic. Proc. Natl. Acad. Sci. USA 2007, 104, 17977-17982.

89. Zoccali, C.; Catalano, C.; Rastelli, S. Blood pressure control: Hydrogen sulfide, a new gasotransmitter, takes stage. Nephrol. Dial. Transplant. 2009, 24, 1394-1396.

90. Epstein, F.H. Cardiovascular disease epidemiology: A journey from the past into the future. Circulation 1996, 93, 1755-1764.

91. Hobauer, R.; Frass, M.; Gmeiner, B.; Kaye, A.D.; Frost, E.A. Garlic extract (Allium sativum) reduces migration of neutrophils trought endothelial cell monolayers. Middle East J. Anesthesiol. 2000, 15, 649-650.

92. Gu, X.; Wu, H.; Fu, P. Allicin attenuates inflammation and suppresses HLA-B27 protein expression in ankylosing spondylitis mice. Biomed Res. Int. 2013, 171573:1-171573:6.

93. Sela, U.R.I.; Ganor, S.; Hecht, I.; Brill, A.; Miron, T.; Rabinkov, A.; Sela, U. Allicin inhibits SDF-1 a -induced $\mathrm{T}$ cell interactions with fibronectin and endothelial cells by down-regulating cytoskeleton rearrangement, Pyk-2 phosphorylation and VLA-4 expression. Immunology 2004, 111,391-399.

94. Prager-Khoutorsky, M.; Goncharov, I.; Rabinkov, A.; Mirelman, D.; Geiger, B.; Bershadsky, A.D. Allicin inhibits cell polarization, migration and division via its direct effect on microtubules. Cell Motil. Cytoskeleton 2007, 64, 321-337.

95. Tocque, B.; Delumeau, I.; Parker, F.; Maurier, F.; Multon, M.C.; Schweighoffer, F. Ras-GTPase activating protein (GAP): A putative effector for Ras. Cell Signal. 1997, 9, 153-158. 
96. Patya, M. Allicin stimulates lymphocytes and elicits an antitumor effect: A possible role of p21ras. Int. Immunol. 2004, 16, 275-281.

97. Ellerin, T.; Rubin, R.H.; Weinblatt, M.E. Infections and anti-tumor necrosis factor alpha therapy. Arthritis Rheum. 2003, 48, 3013-3022.

98. Lang, A.; Lahav, M.; Sakhnini, E.; Barshack, I.; Fidder, H.H.; Avidan, B.; Bardan, E.; Hershkoviz, R.; Bar-Meir, S.; Chowers, Y. Allicin inhibits spontaneous and TNF-alpha induced secretion of proinflammatory cytokines and chemokines from intestinal epithelial cells. Clin. Nutr. 2004, 23, 1199-1208.

99. Parameswaran, N.; Patial, S. Tumor necrosis factor- $\alpha$ signaling in macrophages. Crit. Rev. Eukaryot. 2010, 20, 87-103.

100. Haase, H.; Hieke, N.; Plum, L.M.; Gruhlke, M.C.H.; Slusarenko, A.J.; Rink, L. Impact of allicin on macrophage activity. Food Chem. 2012, 134, 141-148.

101. Dirsch, V.M.; Kiemer, A.K.; Wagner, H.; Vollmar, A.M. Effect of allicin and ajoene, two compounds of garlic, on inducible nitric oxide synthase. Atherosclerosis 1998, 139, 333-339.

102. Dipaolo, J.A.; Carruthers, C. The effect of allicin from garlic on tumor growth. Cancer Res. 1960, 20, 431-434.

103. Miron, T.; Wilchek, M.; Sharp, A.; Nakagawa, Y.; Naoi, M.; Nozawa, Y.; Akao, Y. Allicin inhibits cell growth and induces apoptosis through the mitochondrial pathway in HL60 and U937 cells. J. Nutr. Biochem. 2008, 19, 524-535.

104. Oommen, S.; Anto, R.J.; Srinivas, G.; Karunagaran, D. Allicin (from garlic) induces caspase-mediated apoptosis in cancer cells. Eur. J. Pharmacol. 2004, 485, 97-103.

105. Park, S.-Y.; Cho, S.-J.; Kwon, H.-C.; Lee, K.-R.; Rhee, D.-K.; Pyo, S. Caspase-independent cell death by allicin in human epithelial carcinoma cells: involvement of PKA. Cancer Lett. 2005, 224, 123-132.

106. Bat-Chen, W.; Golan, T.; Peri, I.; Ludmer, Z.; Schwartz, B. Allicin purified from fresh garlic cloves induces apoptosis in colon cancer cells via Nrf2. Nutr. Cancer 2010, 62, 947-957.

107. Loboda, A.; Was, H.; Jozkowicz, A.; Dulak, J. Janus face of Nrf2-HO-1 axis in cancer-Friend in chemoprevention, foe in anticancer therapy. Lung Cancer 2008, 60, 1-3.

108. Niture, S.K.; Jaiswal, A.K. Nrf2 protein up-regulates antiapoptotic protein Bcl-2 and prevents cellular apoptosis. J. Biol. Chem. 2012, 287, 9873-9886.

109. Niture, S.K.; Jaiswal, A.K. Nrf2-induced antiapoptotic Bcl-xL protein enhances cell survival and drug resistance. Free Radic. Biol. Med. 2013, 57, 119-131.

110. Cha, J.H.; Choi, Y.J.; Cha, S.H.; Choi, C.H.; Cho, W.H. Allicin inhibits cell growth and induces apoptosis in U87MG human glioblastoma cells through an ERK-dependent pathway. Oncol. Rep. 2012, 28, 41-48.

111. Arditti, F.D.; Rabinkov, A.; Miron, T.; Reisner, Y.; Berrebi, A.; Wilchek, M.; Mirelman, D. Apoptotic killing of B-chronic lymphocytic leukemia tumor cells by allicin generated in situ using a rituximab-alliinase conjugate Apoptotic killing of B-chronic lymphocytic leukemia tumor cells by allicin generated in situ using a rituximab-alliinase con. Mol. Cancer Ther. 2005, 4, 325-332. 
112. Parisy, V.; Poinssot, B.; Owsianowski, L.; Buchala, A.; Glazebrook, J.; Mauch, F. Identification of PAD2 as a gamma-glutamylcysteine synthetase highlights the importance of glutathione in disease resistance of Arabidopsis. Plant J. 2007, 49, 159-172.

113. Rabinkov, A.; Miron, T.; Mirelman, D.; Wilchek, M.; Glozman, S.; Yavin, E.; Weiner, L. S-Allylmercaptoglutathione: The reaction product of allicin with glutathione possesses SH-modifying and antioxidant properties. Biochim. Biophys. Acta 2000, 1499, 144-153.

114. Schneider, C.A.; Rasband, W.S.; Eliceiri, K.W. NIH Image to ImageJ: 25 years of image analysis. Nat. Methods 2012, 9, 671-675.

115. Hammer, Ø.; Harper, D.A.T.; Ryan, P.D. Paleontological statistics software package for education and data analysis. Palaeontol. Electron. 2001, 4, 9-18.

116. Noctor, G.; Gomez, L.; Vanacker, H.; Foyer, C.H. Interactions between biosynthesis, compartmentation and transport in the control of glutathione homeostasis and signalling. J. Exp. Bot. 2002, 53, 1283-1304.

(C) 2014 by the authors; licensee MDPI, Basel, Switzerland. This article is an open access article distributed under the terms and conditions of the Creative Commons Attribution license (http://creativecommons.org/licenses/by/3.0/). 